\title{
ON THE MANUFACTURE OF HEMP AND WIRE ROPE.
}

By Mr. CHARLES P. B. SHELLEY, OF LONDON.

Ropes are mainly constructed either of the fibres of the Hemp plant (cannabis sativa) or of Iron Wire. Other vegetable substances and other metal wires are also used; but in the present paper only the two important manufactures of hemp rope and iron wire rope are referred to: and as the treatment of the hemp fibres and manufacture of them into rope is quite different from the formation of iron wire rope, the subject naturally divides itself into two branches.

Hemp Rope.-Of the other substances besides hemp which have been found useful and profitable for rope making, the most important are- " manilla", the fibres of which are obtained from the bark of a wild species of banana grown in the Philippine islands, manufactured into a rope commonly known as "white rope"; jute, grown in Bengal, the fibres of which are used for adulterating hemp; cocoa-nut fibre for inferior ropes; Indian hemp or "sunn", the high price of which however keeps it out of the market; and Spanish grass or "esparto". Of these " manilla" is the most common substitute for hemp. The machinery employed for manufacturing any one of these several fibres into rope is similar with slight modifications to that employed for hemp. The intestines, hide, and hair of animals are sometimes used for rope for special purposes; and the Romans are said to have formed ropes by binding together rushes (junci), whence the name "junk" for cable is believed to be derived. A variety of specimens of hemp and of other fibres, together with ropes of different makes, are exhibited, which have been kindly furnished to the writer by Messrs. Wright of Millwall. The manufacture of hemp ropes is still carried on by hand, the ingenions machinery invented for the purpose by the late Capt. Joseph Huddart, and for some time employed at Deptford dockyard, having been abandoned and the old plan of hand making again reverted to. 
The hemp plant from which the fibre is derived consists of a woody cylindrical stem, surrounded by a fibrous peel held together by a glutinous substance, the whole being protected by a fine epidermis or skin. The fibrous part, which is the portion used in the manufacture of ropes, is strong, flexible, and tenacious; but the woody core and the external skin are useless, and it is necessary that they shall be separated from the fibres. This is effected by "retting", that is by soaking the hemp stalks in water and allowing fermentation to take place, thus rotting the woody and glutinous parts and leaving the fibres free. The hemp is pulled up by the roots, and the flowers and leaves stripped off, and it is then immersed in a pond or running stream where it is allowed to remain until fermentation takes place, the time of immersion being dependent upon the degree of humidity and temperature of the atmosphere and also upon the quality and growth of the stalks. There are many objections however to this system of retting; the principal is that the stalks not all being of the same strength of growth, and also occupying different positions in the immersed heap, some are liable to suffer from decomposition and be weakened while others may not be sufficiently steeped, rendering it difficult in the processes which follow to separate the woody matter from the fibres, and thus rendering the hemp harsh and inelastic. Another serious objection is that the vapour arising from the putrefaction of the stalks renders the neighbourhood of the stream or pond where the retting is carried on unhealthy. Moreover this mode of retting unaroidably deteriorates and wastes the fibre; for a single stem of hemp is said to be composed of 70 to 80 per cent. of wood and 20 to 30 per cent. of fibre, whereas the fibre obtained by the present method does not exceed 16 per cent. and falls as low as 12 per cent., the remainder being wasted in the retting. Several other modes of preparing the stalks have been tried, such as steaming them, treating them with lime water or alkaline solution, and also adding materials to the mass of soaking stalks with a view of inducing speedy fermentation; but generally these plans have failed and there is still room for improvement in this respect. After the stalks have been dried they are broken at a hand break or by rollers, and the woody part is separated by "scutching", somewhat in the same 
way as in the case of flax. The hemp thus prepared is packed in huge bales, each bale of Italian hemp, jute, or manilla, weighing about $2 \frac{1}{2} \mathrm{cwts}$.

In order to form the strongest rope out of a given quantity of material, whether hemp fibres or metallic wire, the fibres should be laid parallel alongside one another and secured at the ends, so that they may take any tensile strain put upon them in the direction of their length; the strength of such a rope will be equal to the strength of each fibre multiplied by the number of fibres in the section. Hemp fibres rarely exceed 4 feet in length, so that the above method of making a rope exceeding 4 feet in length will not apply to that material. In order therefore that the fibres may be securely and continuously connected together, they must be placed parallel to one another with the end of one fibre overlapping the end of its neighbour; and to prevent the fibres slipping from one another, friction is produced amongst them by twisting; but as the strength of the fibres is diminished when they are twisted out of the direction of the tensile strain which they are to sustain, no more twist should be given than is necessary to impart sufficient friction to prevent them from slipping and parting endways. It must be remembered that fibres of hemp, like metallic wires, have not the property of "felting", or uniting into one length by a kind of entanglement or matting together, in the manner common to the fibres of wool and other materials used in spinning. If a bundle of parallel fibres be twisted, those on the outer surface will be stretched and strained considerably more than those near the centre; and the further they are from the centre the more will they be strained. Hence in constructing cordage it is necessary to form or build it up gradually from small bundles. Thus the primary object of the rope maker is to get the longest, finest, and strongest fibres which can be economically obtained; and next to lay them in bundles parallel to one another and in continuous juxtaposition, giving them ultimately such a degree of twist that the friction amongst the fibres of the bundle is equal to their tensile resistance.

When the fibres are laid parallel and in continuous juxtaposition, they are said to form a "sliver"; and the sliver when twisted is said 
to be converted into a "thread" or "yarn"; and a number of yarns laid parallel and in juxtaposition, bound round by an external " serving" of yarn to hold them together, form "selvagee" which is the simplest construction of rope. If each of the yarns in the selvagee bore its fair share of strain, this would be the strongest kind of rope ; but the objection to its more frequent use is that the outside "serving" of yarn frets away and allows water to enter and rot the yarns inside. In order to overcome the objections to selvagee, ropes are made of "strands", each strand consisting of a number of yarns twisted together, the strands being again twisted into the rope; the class of rope depends upon the number of strands and their arrangement. The yarn is twisted in the process of manufacture by a motion to the left from the right, or contrary to the motion of the hands of a watch, producing what is termed in rope making a left-handed twist, being a spiral corresponding to the thread of a right-handed serew. The twist of each strand is in the opposite direction to that of the yarns composing it; and the twist of the rope itself is again in the opposite direction to that of the strands, or in the same direction as that of the yarns.

Ropes are commonly divided into three classes known as " hawserlaid", "shroud-laid", and "cable-laid" ropes. "Hawser-laid" ropes are composed of three strands twisted together; the number of yarns for each strand in different sizes of hawser-laid ropes is dependent on the diameter or number of thread of the yarn. "Shroud-laid". ropes are composed of four strands. "Cable-laid" ropes are composed of three hawser-laid ropes twisted together. "Cablets" are small cable-laid ropes measuring from 1 to 10 inches in girth; larger sizes are termed cables. Shroud and hawser-laid ropes seldom exceed 10 inches in girth. A core or "heart" is used in shroud-laid ropes; it is made of rope and is placed in the centre of the strands, running from end to end of the rope with the strands laid round it. In old worn out ropes the core is always found to be broken in consequence of the stretching of the strands; for the strands being twisted spirally and the core straight, the strands will give more under a load than the core, which cannot therefore be relied upon for adding strength to the rope; but it assists materially in keeping the strands in position 
during the manufacture of the rope by hand. Flat hempen ropes are made of four or six ropes, each composed of three strands, and laid alternately to the right and to the left; these are stretched side by side and sewn through in a zigzag direction.

Before the hemp is spun into yarn it has to be freed from dust and hard knots, and the fibres combed so that they may be separate and parallel to one another. This process is called "Heckling", and is done either by machinery or by manual labour; the machinery for the purpose is similar to that used in the preparation of flax. When done by hand, each man is provided with two combs or "heckles", one coarse and the other fine. The heckle is formed of a number of straight sharp-pointed steel pins fixed with the points upwards in an inclined board; the length of the pins, their thickness, and pitch or distance from centre to centre, vary with the material to be heckled, those used for manilla being much finer and closer together than those used for hemp : the pins for heckling hemp are about 10 inches long and about $2 \frac{1}{2}$ inches pitch centre to centre. The dresser after untying and opening one of the heads of hemp takes hold of the fibres at about the middle of their length and throws one end of them loosely over the pins, and pulls the bundle towards him; this is repeated until about half the length has been thoroughly combed by drawing through the heckles. The bundle is then turned end for end and the other half heckled in the same way, after which it is finished on the fine heckles. The hemp is now entirely free from knots and has a glossy silky appearance; it is distinguished as "long hemp" and is said to be "topped"; and the handful of hemp is then doubled in the centre and tied at the ends, in which state it is called "doll" and weighs about 2 lbs. The tow or fibres retained by the heckles are called "shorts", and if the shorts are to be worked into the yarn they are tied up with the bundle of "doll". The dresser applies a little oil occasionally to the points of the prongs for the purpose of reducing the friction; and in dressing manilla, soap is sometimes applied to the fibres for the same purpose, in addition to oiling the heckles. Each bale of Italian hemp, jute, or manilla, weighing $2 \frac{1}{2}$ cwts. or 280 lbs., loses by heckling about $80 \mathrm{lbs}$. of "shorts" and $10 \mathrm{lbs}$. of waste, leaving $190 \mathrm{lbs}$. of "long hemp" from the bale. One dresser heckles in a day 8 cwts. 
(finished weight) of St. Petersburg hemp, or 2 cwts. of manilla, or $1 \frac{1}{2} \mathrm{cwt}$. of jute.

The next process which the fibres undergo is that of Spinning into yarns. Hand spinning is done on a long strip of ground called the rope walk, which is generally covered by a low roof: sometimes the shed has an upper floor with a low roof, and then the spinning is done on the upper floor and the other parts of the manufacture on the ground. The length of the walk and shed is about 1230 feet or a little over 200 fathoms, and the width about 30 feet. The tie beams of the roof are placed every 30 feet or 5 fathoms apart, and carry a row of hooks on the underside. That end of the walk at which the spinning machines are placed is called the "head" or "fore end" of the walk, and the opposite end is the "foot" or "bottom end" of the walk.

The Hand Spinning Machine, shown in Figs. 1 and 2, Plate 46, is formed of two cast iron frames with a band wheel $A$ between them, driven either by a man at the winch handle at the back or by steam power. A band passing round the wheel passes over twelve wood rollers or "whirls" B, $1 \frac{1}{2}$ inch diameter, as shown enlarged in Fig. 3, fixed on steel spindles about $\frac{3}{8}$ inch diameter which revolve in notches or bearings in the brass dises $\mathrm{C}$ screwed in the frames of the machine : the spindles are kept in their bearings by a riband of wrought iron screwed upon the outside of the frame. On the back end of the spindle is a shoulder, and between this and the brass dise is a loose collar, to take the pull of the yarns in spinning; the spindle is kept in by a finger $D$ fixed on the back of the frame. The front end of the spindle is drawn out into a hook $\mathrm{E}$. The notches in the brasses $\mathrm{C}$, shown enlarged in Fig. 4, are for the purpose of forming fresh bearings for the spindles; there are eight notches in each brass, and when one notch is worn down the brass is turned to bring another notch round: when the whole of the notches are worn down a new brass is put in. The twelve hooks and "whirls" are set upon the semicircular upper part of the machine, and are made to revolve by the band which passes over them from the driving wheel $A$. 
Each spinner before beginning to spin takes up a bundle of hemp sufficient in quantity to spin one "thread" of yarn of the required length; he places the "bight" or middle of the length of the fibres in front of him, and turns the ends round his waist, crossing them behind. If the "shorts" are to be worked into the yarn they are tucked below the bight. Each spinner carries in his right hand a piece of stout list. There are twelve spinners to each machine, one to each hook. The spinner draws from the bight or front of the bundle round his waist a sufficient quantity of fibres for the size of the yarn or thread about to be spun, thus forming a "sliver", which he twists with his fingers and hooks the bight of the sliver on to one of the revolving hooks of the machine. $\mathrm{He}$ then walks backwards towards the bottom of the rope walk, drawing the hemp from his waist and forming a sliver with his left hand, pulling some of the fibres back if they come forward too quickly and drawing some forward if there are not enough to keep up the required size of yarn. The sliver passes through his right hand, with which by means of the piece of list he firmly grips it, so as to "form" the yarn. The spinner thus prepares the sliver and forms the yarn, while the machine gives it the twist. Care must be taken not to place the ends of one set of fibres too near to the ends of the next set, not giving them sufficient lap, otherwise the yarn will part by the fibres slipping endways from one another ; and also to keep the fibres even and regular in thickness, in order that the yarn may be of equal strength throughout. The spinner's pace in walking backwards must be uniform and in accordance with the speed of the revolving whirls. The speed of the whirls and the amount of twist of the yarn is dependent upon the quality of the rope to be manufactured.

The twelve spinners are divided into three sets of four each; four risers, four middlemen, and four leaders. The four risers work from the four hooks on the left side of the machine, the four middlemen from the four middle hooks, and the four leaders from the four hooks on the right of the machine. All the twelve spinners start at once from the machine in the morning. The four risers spin down the walk a yarn 1-3rd of 160 fathoms long, and then stop, while the middlemen and leaders continue to spin past them. The four yarns of the risers 
are now unhooked from the whirls by a man at the top of the walk, and are passed each through a hole $F$ in the frame of the spinning machine, Fig. 1, Plate 46, to a reel at the back, upon which they are wound; the men at the bottom end of the yarns still hold on so as to prevent the yarn from untwisting, and follow it up to the machine as it is wound on to the reel. They then twist the ends of these yarns on to one of the holding pins $G$ on the cross bar of the machine frame, and start spinning again with four fresh yarns which they will this time spin down to the whole length of 160 fathoms before stopping. The four middlemen spin down the walk a yarn 2-3rds of 160 fathoms long, and then stop, while the leaders still go on and pass them. Their four yarns are taken off the hooks of the machine and spliced on to the ends of the four yarns which were left on the holding pin by the risers; the yarns of the four middlemen are then wound on to the reel, the men following them up the walk and fastening the ends on to one of the holding pins: the middlemen then start fresh yarns of 160 fathoms length and spin down the walk. The four leaders spin down the walk a yarn 160 fathoms long, and then they also stop, and their four yarns are taken off the hooks and spliced on to the ends of the four yarns left on the holding pin by the middlemen; the yarns of. the leaders are then wound up on the reel, followed up by the men. So they go on till breakfast time, the three sets of men never being up at the machine together, and never more than four being there at one time, so that the three sets are always separated. After breakfast the risers commence with the $2-3$ rds lengths and the middlemen with the 1-3rd lengths, and thus the quantity of yarn spun is equalised between them.

As the spinner proceeds down the walk he tosses the yarn with his left hand on to one of the hooks in the rafters in order to support it; and in coming back he jerks it off again. The distances of 1-3rd, 2-3rds, and 160 fathoms are chalked on the side of the shed, and as the spinners of each set come to the distance they shake their yarns and thus signal to the man at the machine for the yarns to be unhooked and reeled up. Each spinner is paid in London $9 d$. for spinning six threads or yarns, each 160 fathoms long; this is called "one quarter's work", and each spinner spins four threads in an hour. 
The yarns are distinguished and designated by their size or number of thread, every size being numbered; the ordinary numbers, beginning with the coarsest yarn and going to the finest, are 18, 20, 25, 30, and 40. No. 20 is the most usual size and is employed for "London staple cordage"; No. 25 is used for government yarns, No. 30 for bolt rope yarns or the finest description of cordage, and No. 40 for whale lines. In spinning No. 20 size the "shorts" are always worked in with the "long hemp"; but for finer sizes, 25, 30, and 40, "long hemp" alone is used, in order that the yarn may be even and smooth. The size of the yarn is determined by the number required in each strand to make a rope of 3 inches girth with three strands; thus the size of No. 20 yarn is such that 20 yarns in each strand will make a rope of 3 inches girth with three strands. No. 20 is said to be the usual "grist"; Nos. 25, 30, and 40, are said to be finer "grists".

If the cordage is to be tarred, it is done at this stage of the manufacture, before the yarns are formed into strands; but the process of tarring the yarns will be described subsequently.

When the reel behind the spinning machine has been filled with the four lengths of yarns spun, it is taken to the Winding Machine, shown in Figs. 5 and 6, Plate 47, which separates the four yarns on to four separate bobbins $\mathbf{A} \mathbf{A}$, and also reverses the lay of the yarn end for end so that the fibres may lie in the proper direction for passing through the next process. Fig. 5 is a front elevation of half the length of the machine, showing two of the four winding bobbins $A A$; and Fig. 6 is an end elevation. The bobbins are driven from the drum $B$ which extends the whole length of the machine, by means of straps passing round the four riggers $\mathrm{C} \mathrm{C}$ fixed on the vertical spindles that carry the bobbins $A$. The full reel containing the four yarns from the spinning machine is mounted on a temporary frame behind the winding machine, and the ends of the four yarns are led to the bobbins over a sliding bar $D$, which has a vertical reciprocating motion given to it by the cam $E$ and levers $F$, for the purpose of filling the bobbins regularly and equally from end to end. Other forms of winding machines are used, but the principle of construction is the same in all. When the 
four bobbins are filled they are replaced by empty ones, until the whole of the reel from the spinning machine is wound off upon bobbins. The four full bobbins are then taken away and placed vertically in a large wooden frame called the bobbin frame, which holds from 150 to 200 bobbins. Each bobbin contains about $14 \mathrm{lbs}$. of yarn.

The next process is that of twisting a number of yarns together into a strand, which is termed "Forming" and is done in the "forming" machine and in the shed covering the rope walk. Having ascertained the number or size of the thread that is of sufficient thickness to form the required strand, the number of yarns corresponding to that size of thread are selected; and the ends of the yarns of this size are drawn from the bobbins and brought in a converging direction to a square iron plate, called the "register" plate, perforated with a number of round holes. Each yarn is made to pass through a separate hole in the register plate, and the yarns all converge thence into one common point through the forming board, in which is a taper steel tube with a trumpet-mouthed taper hole through it. The hole in the tube varies in diameter for each size of strand and is selected by a gange: the diameter of the tube for one of the strands for a rope of 3 inches girth is 8-16ths inch at the small end and 9-16ths inch at the large end, and for the strands of a rope of 2 inches girth it is 5-16ths inch at the small end and 7-16ths inch at the large. The convergent yarns are entered into the tube at the large trumpetmouthed end, and are forced through, fitting tightly into the tube ; they are thus squeezed together previously to being attached to the forming machine.

The Forming Machine for twisting the hemp yarns into strands is shown in Fig. 7, Plate 48. It is mounted on wheels and made to travel along the length of the rope walk by the endless rope $A$, called the "fly rope", which passes round pulleys at the top and bottom of the walk and acts as a driving rope, being driven by an engine. This fly rope takes a turn round the whelp wheel $\mathrm{B}$, which gives motion by gearing to the $\operatorname{drum} \mathrm{C}$ and the twisting hooks or "nibs" D for forming the strands. A fixed rope $\mathrm{E}$ called the "ground rope", made fast at the ends of the walk, is coiled round the drum $\mathrm{C}$, so that by the revolution of the drum the machine is made to 
travel along the walk. During the travel of the machine the yarns hooked upon each nib are drawn out and twisted together into a strand; each nib taking the number of yarns required to form the strand. The speed of revolution of the hooks is regulated according to the kind of rope into which the strands are to be made; and the great object is to adjust the rate of travel of the machine in relation to the speed of the houks so that the strands may receive the proper amount of twist in a given length. For this purpose the staves of the drum $\mathrm{O}$ which gives the travel of the machine are made capable of being shifted to or from the centre of the drum by means of adjusting screws, so as to diminish or increase the rate of travel.

In the next process the strands are "laid" into a rope by two "Laying" Machines, one at the upper end of the walk and the other at the lower end, shown in Figs. 8 and 11, Plates 49 and 50. In this process, instead of being twisted together as the yarns are in the previous "forming" process, the strands are placed or "laid" in their spiral position in the rope without being twisted. The laying machine at the upper end of the walk, Fig. 8, Plate 49 , is fixed, and the three strands to form the rope are attached to the hooks $D$, which are made to revolve in a similar manner to those in the previous forming machine, by the fly rope passing round the wheel $\mathbf{B}$. The lower end laying machine, Fig. 11, Plate 50, is left free to travel part way up the walk as the length of the strands becomes shortened by their being laid into a spiral in the rope. The wheel $B$ here drives the two "forelocks" A A, to one or other of which the strands are made fast, according as the twist of the rope is to be right-handed or left-handed. The three strands for the rope are stretched tight along the length of the walk from the hooks $D$ of the laying machine at the upper end to the forelock $A$ of the lower laying machine, and are supported off the ground and kept separated by means of posts, called " samson posts", placed at every 5 fathoms length, with pegs to carry the strands. A taper piece of wood with three grooves, called the "laying top.", shown enlarged in Figs. 9 and 10 , Plate 49 , is then inserted between the strands close to the lower machine, with its smaller end towards the forelock $A$, one of the strands lying in each of 
the grooves. A transverse hole is made through the laying top, through which is passed the "top stick" or handle that the top is held by. The laying tops are made of various sizes according to the size of rope required: for a rope of 3 inches girth the top is 12 inches long, 10 inches diameter at the larger end, and 8 inches at the smaller. When the rope is more than $3 \frac{1}{2}$ inches in girth, a "top cart" is used for supporting the top.

The laying machines being now put in motion, the revolution of the forelock A, Fig. 11, Plate 50, gives the twist or "hard" of the rope, while the laying top is firmly held by the handle from turning. The hooks D, Fig. 8, Plate 49 , at the other ends of the strands are made to revolve in the opposite direction to the forelock $A$ which is twisting the rope, so that the twist put into each of the individual strands at the point where they are united into the rope immediately behind the laying top is taken out again by the hooks at the upper end. The laying top is gradually pressed forwards ly the closing of the strands upon one another behind it; its motion requires to be very regular, and it is prevented from moving forwards too fast by a "tail" or piece of rope attached to the top handle, which is coiled round the rope already twisted, and thus acts as a drag to the top. The two laying machines must be driven at exactly the proper speed relatively to each other, so that the twist put into the separate strands at the laying top may be exactly nentralised by the revolution of the hooks: otherwise if the hooks revolve too slow, they will partially untwist the individual strands, since the twist of the yarns in each strand is in the contrary direction to that of the strands in the rope; or if too fast, the strands will become twisted tighter. In order that the man holding the laying top may find out how the machines are working, whether too fast or too slow relatively to each other, he makes a mark on one of the strands close to one of the supporting posts: if the strands are being twisted too fast by the hooks of the upper laying machine, the mark on the strand advances towards the upper end of the walk, from the yarns themselves becoming twisted tighter together in each strand, whereby the length of the strand is shortened; but if too slow, the mark recedes towards the lower end, from the partial untwisting and consequent lengthening of the 
individual strands. In laying the strands care is required with regard to the angle that the strands take. Should the tension on the strands become unequal, the required additional twist is given to those which have got slack by throwing out of gear those hooks of the upper laying machine to which the tighter strands are attached, and allowing the others to continue revolving until all the strands have again become equally strained. As the formation of the rope proceeds, the lower laying machine is gradually drawn up the walk by the shortening of the strands as they are laid together into the rope; and weights called "press weights" are placed on the frame of the machine to retard its motion and hold the rope tight enough during the laying. Formed strands of 180 fathoms length will make 120 fathoms of hawser-laid rope; the length of the strands will be determined by the length of rope required.

After the rope is taken off the laying machines, it is coiled on to a drum driven by steam power, being guided from end to end of the drum by the workman, whose hands are protected by a piece of old cordage twisted on the rope that is being coiled; this gives a polish and finish to the surface of the rope.

The previous description has referred only to ropes manufactured by hand. In the application of machinery to this manufacture, which is next to be considered, Mr. Cartwright appears to have invented the first rope making machine, which is the basis of others since constructed, his "Cordelier" having been brought out in 1792. Fig. 12, Plate 51, shows a sketch of the cordelier, which revolves on the horizontal shaft $A$, the laying top $B$ serving as the bearing at one end of the shaft, having holes through it for the strands to pass through. In the discs $\mathrm{C} C$ fixed on the shaft $\mathrm{A}$ are centred the three horizontal spool frames D, carrying the spools $\mathrm{E}$ which contain the three strands to be laid together. As the cordelier revolves, the axes of the spools are preserved constantly parallel to themselves by the spool frames $\mathrm{D}$ being made to rotate on their bearings once for every revolution of the machine, by means of the pinions $\mathbf{F}$ on the spool frame bearings, and the counter wheels $G$ gearing into the central dead wheel $H$, which is of the same diameter as the pinions $F$ and is 
held stationary while the shaft $\mathbf{A}$ revolves within it. The bearings at the other end of the spool frames D are hollow, for the strands to pass through to the laying top $B$. The strand is drawn off the spool by the pair of delivering rollers $I$, which receive motion by a worm wheel $J$ on the axis of one of them gearing into the worm $\mathrm{K}$ within which the spool frame revolves. The drawing rollers $L \mathrm{~L}$ draw the finished rope forwards as fast as it is made, and hold it from turning.

This machinery was a few years afterwards improved upon by Capt. Huddart, who constructed machines that were used for a number of years at the Deptford dockyard for spinning the yarns and for the manufacture of ropes and cables; and the author is mainly indebted for the following particulars of the construction of this machinery to a description and drawings given in the Professional Papers of the Royal Engineers by Mr. John Miers.

The Spinning Machine for converting sliver into yarn is shown in Figs. 13 and 14, Plate 52. Fig. 13 is a portion of the front elevation of the machine, showing four of the twelve spinning tubes A A; and Fig. 14 is a transverse section. The sliver, previously formed by another machine, is contained in the twelve cans $B$, which are driven rather faster than the spinning tubes $A$ in order to give a slight preparatory twist to the sliver. The spinning tube $A$, shown enlarged in Figs. 15 and 16, has a spring clip $C$ at the top, which grips the thread spun from the sliver and twists it with great rapidity, thus effecting the spinning. The thread so formed is then subjected to a considerable amount of tension by being drawn through the compressing jaws D, Figs. 15 and 17, and round the stretching pulleys $E, F$, and $G$, Fig. 14, the last of which is a double pulley with two grooves. The thread passes first over the pulley $\mathbf{E}$, then under one of the grooves in the pulley $G$, over the pulley $F$, and again over the second groove of the pulley $G$, whence it passes away to a winding drum at the back of the machine. The main driving shaft of the machine is driven from the engine by a belt over the fast and loose pulleys $H$. There are three horizontal winding drums behind the machine, upon which the yarns are wound, each drum taking the yarns from four of the spinning tubes: the yarns are delivered upon the drums through holes in a longitudinal traversing bar, which is moved endways backwards 
and forwards by a rack and pinion so as to guide the yarns from end to end of the drums alternately.

If the ropes are to be tarred the tar is applied to the yarns on leaving the spinning machine. For this purpose they are first wound off from the drum behind the spinning machine upon a winder called a "whimwam", made of a light open frame of iron and wood revolving on a horizontal shaft. The loose ends of the four yarns on the drum are attached to a hook at the right end of the winder, which is then turned by a winch handle to wind the yarns on, the yarns being guided on from end to end by a traversing plate with four holes in it which receives the required traverse motion from the shaft of the winder. On reaching the left end of the winder the yarns are doubled round the hook at that end, and the winch is then turned in the opposite direction, winding the yarns on till they reach the right end, where they are similarly doubled round the hook at that end, and the winding is then again reversed. When a sufficient quantity of yarn has been put on the winder, the hook at one end is taken out and the yarn is uncoiled from the winder, thus forming a long skein called a "hanl", which is then coiled upon a small circular revolving platform called a "turntable", about 4 feet diameter, mounted on wheels. The haul of yarns is then taken to the tarring shed, and uncoiled from the turntable into a cauldron of tar heated by fire or steam ; one end of the haul is lifted from the tar, and by means of a capstan is drawn through a sliding nipper or squeezer for the purpose of squeezing out the superfluous tar from the yarns. After the haul has lain for some time, the longer the better, the four yarns are separated and wound on to four bobbins by the winding machine previously described; and are then passed to the bobbin frame ready for being twisted into strands. Capt. Huddart did not make the yarns into a haul previous to tarring, but passed them from bobbins direct from the spinning machine throngh the tar and thence through nippers to the register plate of his registering machine about to be described. The length of a haul is 55 fathoms; it contains about 144 threads and takes about 20 minutes to pass through the squeezer from the tar cauldron, that is about 16 feet in a minute. The tar used 
should be the best Archangel tar, of a good bright colour, and heated to a temperature of $212^{\circ} \mathrm{Fahr}$. The usual proportion of tar remaining in the yarns is from one quarter to one fifth of the weight of the untarred yarns. The yarns when tarred ought to be of a bright brown colour.

The "Registering" Machine, shown in plan in Fig. 18, Plate 53, is for the purpose of twisting the yarns into a strand and winding the strand upon a drum as fast as it is formed. The whole machine revolves with rapidity on the horizontal bearings $\mathrm{A} B$, being connected with the driving power by a sliding friction clutch at $B$. The strand enters through the hollow bearing $A$, which grips it tight and thus twists the yarns into the strand by its revolution. The strand is drawn in by the pair of drawing pulleys $\mathrm{C}$, talking half a turn round each, and is delivered upon the winding drum $D$ by the guiding frame $\mathrm{E}$, which is made to move from end to end of the drum by means of a stud on the frame working in a spiral groove cut in the barrel F. The drawing pulleys C, winding drum D, and grooved barrel $F$ are all driven from the spur wheel $\mathrm{f}$ gearing into a stationary pinion fixed to the plummer block in which the bearing $A$ revolves. As each successive coil of strand wound on the drum $D$ increases its diameter, whereby an increased tension would be thrown on the strand, a friction clutch is inserted at $\mathrm{H}$ in the intermediate shaft which communicates the driving motion from the drawing pulleys $\mathrm{C}$ to the winding drum $D$, in order to prevent the drum from overwinding the pulleys, the friction being adjusted to the exact limit of tension desired in the strand. The guiding frame $\mathrm{E}$ which delivers the strand from end to end of the winding drum vibrates on a centre at $I$, and its rate of travel is varied for different sizes of strand by changing the worm wheel $J$ on the spindle of the grooved barrel $\mathbf{F}$; the universal joint $K$ allows of the driving worm being set at different inclinations for gearing into a larger or smaller worm wheel $\mathrm{J}$.

The strand made by the registering machine is wound off the drum $\mathrm{D}$ on to a loose reel, so that when transferred to the drum of the spool frame in the laying machine it may lie the same way end for end as on the drum $D$, in which state it is ready for being laid into a rope. The length of the strand is measured by passing it over a pulley of definite diameter, to which is attached a counter with a dial 
indicating the number of fathoms of strand that have passed over the pulley.

The Rope Laying Machine for laying the hemp strands into rope is shown in Figs. 19 to 22, Plates 54, 55, and 56. Fig. 19, Plate 54, is a general elevation; Fig. 20, Plate 55, a plan at the top, and Fig. 21 a sectional plan through the spool frames; Fig. 22, Plate 56, is a side elevation of one of the spool frames to a larger scale. The three spools A, Fig. 19, Plate 54, filled with strand from the registering machine last described, are carried in the vertical spool frames $\mathbf{B}$, which are centered at top and bottom in the main frame $\mathbf{C}$ of the machine. The entire machine revolves round the fixed centre shaft, and is driven by the small bevil pinion $\mathrm{D}$ gearing into the wheel $\mathbf{E}$ at the bottom of the main frame $\mathrm{C}$. The spool frames $\mathrm{B}$ are made to rotate on their axes during the revolution of the machine by means of the pinions $\mathbf{F}$ on the spool frames and the connter wheels $G$ gearing into the dead wheel $\mathrm{H}$, which remains stationary, being fixed on the centre shaft of the machine. If the pinions $F$ were of exactly the same diameter as the dead wheel $H$, the spool frames would make exactly one rotation on their axes for each revolution of the machine, and the spools would be preserved constantly parallel to themselves while the machine revolved, so that the strands would be laid into the rope without any additional twist in the individual strands. But in order to ensure the yarns in each strand being thoroughly closed upon one another, a slight additional twist or "forehard" is given to each strand in the act of laying it into the rope, by making the spool frames perform rather more than one rotation on their axes for each revolution of the machine, since the twist of the yarns in each strand is in the contrary direction to the twist of the strands in the rope. The pinions $F$ on the spool frames are therefore made of smaller diameter than the dead wheel $\mathrm{H}$ in the proportion of 13 to 14 . From the spools $A$ the strands are drawn off round the stretching pulleys II, as shown dotted in Fig. 22, Plate 56, which are driven by bevil gearing and pinions $J$ from a dead wheel fixed on the centre shaft at the top of the machine, with counter wheels and pinions $K$ similar to those at the bottom. The strand is pressed tight into the 
groove of the upper stretching pulley I by the small tightening pulley L, Figs. 22 and 23. The spool A is retarded from unwinding too fast by a friction break which is adjusted to any degree of tightness required. The strands pass up through the hollow bearings at the top of the spool frames $B$ and through the pinions $K$, and are curved over the oblique guiding rollers $M$, which are fixed at varying inclinations in order to prevent the strands from slipping off. The three strands then unite at the centre and are laid together into the rope by the revolution of the machine, each strand being laid into the rope with the required amount of "forehard" by the simultaneous rotation of its own spool frame in the contrary direction to the machine. The newly made rope is carried upwards to another machine, where it is stretched over and under three pulleys driven by steam power ; and as it passes from the last pulley it is compressed by a roller kept against the rope by a strong steel spring. It is afterwards finally coiled away in a warehouse.

There were three rope laying machines at Devonport dockyard and they were calculated to make about 3000 tons of cordage per year of 313 days. Of this amount the largest machine would make 2000 tons of cables and hawsers of large size, the cables ranging from 14 to 24 inches girth and the hawsers from $7 \frac{1}{2}$ to $12 \frac{1}{2}$ inches girth; the second machine of intermediate size would make 700 tons of cable-laid ropes from 8 to 16 inches girth and hawsers from $5 \frac{1}{2}$ to $7 \frac{1}{2}$ inches girth; and the smallest machine would make 300 tons of cablets from $5 \frac{1}{2}$ to $7 \frac{1}{2}$ inches girth and shroud-laid ropes from $3 \frac{1}{2}$ to 5 inches girth. The average cost including all charges of the establishment, engine power, repairs of machinery \&c., is said not to have exceeded $17 s .4 d$. per ton of cordage made, when the whole machinery was employed to the fullest extent of its capability; the cost by hand at the same period being stated to be $24 s$. per ton.

The Strength of hemp rope varies considerably, and depends principally on the quality of the hemp from which it is made, the number of yarns composing the strands, and the manner in which the ropes are laid. The average strength of each yarn in hawser-laid ropes is found to be greatest with the smaller sizes of ropes. Shroud-laid 
rope made with four strands is about one fifth weaker than hawser-laid made with three strands, on account of the additional twist or "hard" which is given to the shroud-laid; and cable-laid rope is about one third weaker than hawser-laid rope. The strength of these three different lays is therefore in the proportion of cable-laid 10, shroudlaid 12, and hawser-laid 15 . The relative breaking weights of ropes made from the three most ordinarily used materials are stated to be as follows : taking the breaking weight of St. Petersburg hemp rope at 100 , that of Italian hemp rope is 107 , and that of manilla rope 73 . Tarred rope is weaker than untarred, other circumstances being the same; for the quality of the tar seriously affects the strength of the rope. Hence the strongest ropes are hawser-laid or three-strand ropes made of untarred Italian or Russian hemp.

Wire Rope.-The second branch of the subject of the present paper is the manufacture of Iron Wire Rope, which although at first made by hand is now made exclusively by machinery; and the writer is indebted to Mr. Archibald Smith for kindly furnishing the information on this branch of the subject.

Wire ropes were used as early as 39 years ago for the supporting cables of a suspension bridge at Geneva; and also for the Freiburg suspension bridge of 807 feet clear span, erected 27 years ago. The wire ropes in the latter case, shown in Fig. 24, Plate 57, are constructed of twenty bundles or strands of straight iron wire 0.125 inch diameter, stretched parallel, forming a rope $5 \frac{1}{8}$ inches diameter, and bound round with wire at 2 feet intervals.

The first form of wire rope regularly manufactured was made about 27 years ago, and was known as "Selvagee", shown in Figs. 25 and 26, Plate 57. It consisted of a number of hard or unannealed wires, of about 12 to 16 wire-gauge or 0.110 to 0.065 inch diameter, which were stretched parallel and bound together by a fine wire of about 20 wire-gauge or 0.036 inch diameter, wound spirally around; after which a "parcelling" of woollen list was also wound round in the contrary direction, with the edges lapped so as to cover the wires entirely : the rope was completed by a service of tarred yarn wound on in the contrary direction to the list. The. 
method of making the rope was simply to warp or stretch the wires at a uniform tension over two hooks set at the distance of the length of rope required to be made, passing the wires backwards and forwards over the hooks as many times as was necessary to make up the size required. A solution of india-rubber boiled down in linseed oil with a mixture of resin and tar was rubbed carefully into the body of the rope, previous tò binding up; and after the binding wire had been wound on, the solution was again applied to the exterior wires to prevent oxidation, the process of galvanising being unknown or not practised at that time. The "parcelling" of list was also saturated with. the solution, the yarn being tarred as usual. The binding and parcelling were always done by hand, before the rope was taken off the hooks; but the service of yarn was usually laid on by a machine for that purpose, though occasionally also by hand. The method of attaching the fittings, such as shackles, thimbles, and dead eyes, was either by forming an eye during the process of warping to receive them, or by inserting the end of the rope stripped to the wires into a conical socket attached to the shackle, and turning back the ends of the wires so as to prevent the rope being drawn out. But more generally the fittings were "turned in", that is the end of the rope was doubled round and "seized" or bound to the standing part. It will be seen that it was very difficult to splice this form of rope, owing to the absence of twist or "lay".

Ropes thus made were exceedingly rigid and non-elastic, but possessed greater strength than any other construction; in fact the entire strength of the wire was preserved. The "parcelling" and "service" added to the size, but not at all to the strength, being intended only for protecting the wires. The want of elasticity and pliability, together with the difficulty of fitting and the constant wear of the "service" of yarn, acted somewhat prejudicially against the introduction of this first form of wire rope on an extensive scale; yet it was used in the royal navy, and mercantile marine, and also for suspension and tension bridges: for the latter purpose it is still used, especially in California, where a large number of wire rope suspension bridges are now being erected to replace those destroyed by the late floods. 
The machinery for making these "selvagee" ropes consisted simply of the two hooks over which the wire was warped, which were attached to moveable posts set at the required distance asunder. The "serving" machine was a long wood trough extending nearly the entire length of the rope ground, having a revolving shaft at each end with a hook at its extremity, and carrying a fast and loose pulley, over which a driving band passed. The two serving hooks were driven at the same speed of about 400 revolutions per minute: and the shifting forks of the driving bands were connected by a cord extending throughout the length of the ground, so that the workman could stop or start the machine at any part. An ordinary serving mallet was employed for laying on the yarn, and was guided by the workman who also regulated the tension, the yarn being supplied from reels hung overhead.

The next description of wire rope was known as "Formed" rope, shown in Figs. 27 and 28, Plate 57, and was introduced about 25 years ago. It consisted of a number of soft or annealed wires, usually about 14 wire-gauge or 0.085 inch diameter, "formed" or twisted into a strand, but with little or no regard to regularity; and four of these strands were "laid" into a rope, though this number was not always the same. The number of wires was varied according to the size of rope required, and occasionally the size of wire was altered to suit circumstances. These ropes closely resembled ordinary hemp ropes in appearance. The twist caused by "forming" the strands remained in the wire as a permanent set, and the strands were "laid" together with an extra amount of twist or "forehard" in each strand, which was necessary to keep the rope together. Little or no injury was done to the wire by this process, owing to its being annealed, and also from the length of the twist of the wires in each strand, which was usually about 12 inches pitch; but it would be almost impossible to use hard wire in this manner.

The "formed" wire ropes possessed great pliability and some amount of elasticity; they were readily spliced and fitted, like ordinary ropes, and though not so strong as the "selvagee" wire ropes, they possessed many advantages and were more easily introduced. Their 
adoption for rigging, incline, and traction ropes, became extensive ; and this construction was the first wire rope used on the Blackwall Railway. The small size and soft nature of the wire used offered little resistance to exterior friction, and when employed as incline or running ropes they soon flattened and wore out. The irregularity with which the wires were "formed" or twisted into strands, frequently crossing and recrossing one another, and the great difference in the length of the wires as well as the short "lay" of the ropes, amounting to only $4 \frac{1}{2}$ inches pitch, materially assisted to destroy them. Even when used simply as standing rigging, the wires frequently broke, and the broken ends stuck outwards to the danger of the sailors handling the rigging; and to prevent accidents they were served with yarn, like the "selvagee" rope, after haring been "wormed", that is having a yarn laid in between each strand so as to alter the shape to a round form.

The "formed" wire ropes were originally made on the rope ground by the forming machine usually employed in hemp rope making, shown in Fig. 7, Plate 48. The wires were wound on bobbins placed in racks, just like the hemp yarns, and were led through the perforated register plate, called the "minor" plate, thence through the taper steel nipper or compressing tube, and were attached to the forming machine, which drew out the wires and twisted them together as it travelled backwards towards the other end of the ground. Having arrived there the machine was stopped, and the length of strand thus made was wound upon a large reel, ready to be placed in the laying machine; the use of the reel also enabled a longer length of strand to be made than one length of the ground. For laying the strands into rope, the required number of reels of strand, generally four, were placed in frames mounted on horizontal bearings and geared together. The strands were stretched along the rope ground, being supported and separated on trestles placed at intervals; and were brought together over a "laying top" at the other end of the ground, and attached to a revolving hook. Motion was given to the machine at one end with the four strand reels, and to the hook at the other end in the opposite direction, by means of a "fly rope" or endless driving rope, passing over whelp wheels 
attached to the machine and the hook; the laying top was carried by a workman, who thus regulated the amount of lay or twist. Afterwards the laying top was mounted on a carriage which travelled on rails, and was drawn forwards by another endless rope, called the "ground" rope, which was worked by the machine. This arrangement had the effect of more effectually regulating the lay. "Formed" wire rope is now made in the ordinary vertical machine, which is supplied with extra frames for carrying a large number of bobbins; but for forming the strands the bobbin frames are fixed to the frame of the machine, and not revolving in it, and the wires are brought together through a perforated plate containing the required number of holes.

"Formed" wire ropes were at first well saturated with the solution before described; but afterwards galvanised wire was used for making them. The admiralty still continue to use the "formed" rope entirely, though little is now used elsewhere. "Formed" ropes made of copper wire were used largely in the navy as lightning conductors, the size of the wire being about No. 20 wire-gauge or 0.036 inch diameter, and the rope was made of four strands laid round a small copper wire core. Smaller ropes composed of iron and copper wire were also used as sash lines \&r.

In another kind of wire rope, which was sometimes made on the machinery above described for the manufacture of "formed" rope, the strands were composed of hard wires, usually not exceeding six in number, laid around a core of hemp or wire; and these strands were again laid around a hemp core into a rope. But the objections caused by the rigidity of these ropes prevented any but small sizes being used for some years. Ultimately however these objections were overcome, and this construction has now almost entirely superseded the "formed" rope.

The first Flat wire ropes, made 26 years ago, shown in Figs. 29 and 30 , Plate 57, were composed of from eight to twelve "formed" strands, with the twist alternately right and left handed, made of a number of fine wires usually about 18 or 20 wire-gauge or 0.050 to 0.036 inch diameter. These strands were placed in the position of the warp, in a loom of the ordinary form but greater strength, and were 
woven together with a shoot of strong yarn. Very little twist was put into the strands, as the yarn when woven in kept them in form. These ropes were by no means durable, as the yarn soon wore out, especially at the edges; and their application was very limited.

Flat wire ropes were next made, about 25 years ago, of four or six "formed" ropes, each made of four strands "laid" very long, and alternately right and left handed; these were stretched together side by side and sewn through with six wires of No. 14 or 16 wire-gauge from side to side in a zigzag direction, as shown in Figs. 31 and 32, Plate 57. This was accomplished by carefully inserting a needle of dagger shape between the strands of the ropes, and so making a passage for the wires, which were carefully laid side by side. The round ropes thus bound together resembled the ordinary flat hemp rope in appearance. The process was tedious, on account of the care necessary to avoid penetrating the strands with the needle, which would do great injury to the rope. It was also important that the amount of "lay" or twist in all the ropes composing the flat rope should be exactly the same, otherwise the stretching could not be regular, and some of the strands were liable to be cut when the rope was set to work. With the machinery previously described perfect regularity could not be attained in this respect, and an unsatisfactory result was the consequence.

The next and last construction of wire rope, introduced about 24 years ago, is known as "Laid" rope, shown in Figs. 33 and 34, Plate 57, in which the strands were made of a few wires, seldom exceeding six, "laid" around a core of hemp or wire, the wires of the strand being entirely free from twist, each wire being simply "laid" in a spiral form without any twist in the wire itself, as shown in the diagram, Figs. 35 and 36, Plate 58. Six of these strands were again "laid" without "forehard" or additional twist into a rope, around a core generally of hemp. The size of wire usually varied with the size of the rope, as the total number of wires 36 was seldom varied. The wire was hard or unannealed; and by the system adopted in making, a uniform length was obtained with entire absence of twist. By this means the full strength of the wire was retained, and consequently the 
rope produced was much stronger for the same weight. An increase in size is however caused by the introduction of the hemp cores, which amount to 1-7th of the entire bulk in the case of ropes with six strands of six wires each, the construction now usually adopted.

These "laid" wire ropes, though not so pliable or strong as "formed" ropes, possess many advantages, especially when employed as incline ropes, the hardness and increased size of the wire giving greatly increased durability; and as the prejudice against wire ropes had been partially removed by the introduction of the "formed" ropes, the present "laid" ropes soon began to be extensively used; and within the last few years, since the expiration of many patents formerly existing, the manufacture has increased to a remarkable extent. Wire strand has lately come into extensive use for fencing, very large quantities being exported for that purpose for the Indian railways.

Flat wire ropes also are now made with strands composed of hard wires "laid" together, instead of "formed" as previously, these strands being again "laid" into ropes without any "forehard" or additional twist, and the ropes are then stitched together as previously described. Lately instead of several wires laid side by side being used for stitching, three or four strands have been substituted, each strand containing three wires laid together; the advantage of which is that though several of the single wires may be worn through, the strand still holds the rope together; yet in neatness of appearance the single wires have the preference.

The machinery used in the manufacture of "laid" strands and ropes originally consisted of the ordinary machinery used on rope grounds for laying or closing hemp ropes, the machines at each end of the factory being speeded alike, as previously described.

The next form of machine adopted had simply one hook, mounted in bearings on a fixed frame, and driven by hand or power, to which all the wires composing the strands were attached; these were stretched along the ground, supported at intervals on trestles, till they reached the other end, where they were hooked on to swivels or "lopers". Attached to the lopers were cords passing orer pulleys 
and having weights suspended from them, so as to regulate the tension of each wire and also allow for the shrinkage of the rope in the process of making. When the hook was set in motion, the twist in each wire traversed the entire length of the wire, and escaped at the end by means of the "loper" or swivel. A perforated plate or "laying top" was used, carried by a workman along the ground, regulating the amount of "lay" or twist.

The next machine used, shown in Fig. 40, Plate 59, was a modification of Huddart's hemp rope laying machine, previously described and shown in Fig. 19, Plate 54. In these machines the operation went on continuously until the required length of strand or rope was made, giving rise to the name of "endless" machines; they were also called "vertical" machines, because the main frame carrying the spools revolves on a vertical axis. The first modification of this machine for making wire ropes consisted in altering the gearing for working the spool frames $B$, so that no additional twist or "forehard" was put in the wires as in the strands of hemp ropes, the pinions on the spool frames being now made of exactly the same diameter as the central dead wheel, as shown in the diagram, Fig. 38, Plate 58, causing the spool frames to make exactly one rotation on their axes for each revolution of the machine. Machines of this description were also made to work on a horizontal axis instead of a vertical one; and a balance weight was sometimes attached to each spool frame in the horizontal machines, which by its gravity prevented the spool from twisting the wire and rendered gearing unnecessary for the purpose; but the speed of these machines was limited in consequence.

The next form of machine was that known as a "compound" machine, for producing the entire rope finished at one operation; and may be described as consisting of six stranding machines, like that last described, all mounted on one large frame and revolving horizontally, the necessary motion being given to the machinery to lay the wires into strands and then the strands into rope, without producing any twist in the individual wires. This machine, though a mechanical success, was a commercial failure, and was soon abandoned for the simpler and cheaper plan of first making the strands and then laying them into ropes on separate machines. 
Next some modification was made in the rertical machines, shown in Fig. 40, Plate 59, in the means of preventing twist of the wires during the laying, by employing a centre crank or eccentric and four outer cranks on the spool frames B, as shown in Fig. 40, and in the diagram Fig. 37, Plate 58; and also by substituting chain wheels and pitch chain, as shown in the diagram Fig. 39, Plate 58. Machines were constructed with 36 spools on the revolving frame, connected by cranks to the centre crank; and ropes were thus made with that or any smaller number of untwisted wires in each strand; but this description of rope was rarely used.

In all the vertical and horizontal endless machines that have now been described, all the spools were mounted in one set on a single large revolving table, thus revolving all in one plane; and during the process of laying, the whole weight of the material had to be carried round a circular track varying with the size of the machine from 10 to 40 feet, one revolution being necessary for every lay put into the strand or rope, the Jay varying from 1 inch to 18 inches or more in pitch, according to the size of rope. Machines of this construction were therefore necessarily limited in their speed. Lately however machines have been constructed with the spools arranged in two sets of three each, on two tables one below or behind the other, the spools thus revolving in two plancs; whereby a somewhat increased speed was attained, as the diameter of the revolving tables was reduced. Yet still the spool frames had to be carried round the common centre and caused to rotate on their own centres once for every lay.

The method of joining the lengths of wires was in the first instance by twisting the ends together: afterwards, in the manufacture of "laid" strands, by "tucking", that is cutting out the hemp core about 12 inches from the end of the wire that has run out, and inserting in its place the end of the new length of wire; the rest of the wires are then "laid" up on the new wire as a core for a length of 6 inches, when the new wire is brought out into its right place and the remaining 6 inches of the old wire passed in as the core, on which the laying is again continued till the end of the wire is reached; the proper hemp core is then replaced, and the process of laying resumed as before. Some manufacturers prefer to braze or weld the ends of 
the wires together for joining the lengths, wire as small as No. 16 wiregauge or 0.065 inch diameter being welded by experienced workmen by means of a common portable forge.

An improved construction of wire rope machine has subsequently been introduced, in which the bobbin frames and bobbins are placed one behind another all in the axis of the revolving frame, and remain stationary in that position while the frame alone is made to revolve. By this machine a greatly increased speed is attained, and it is considered that better work is produced. The rate of production is also much increased, as much as 10,000 yards of strand having been made per day of ten hours, instead of only 2500 yards, the usual amount made by the ordinary form of machine.

This machine, the invention of Mr. Archibald Smith of London, is șhown in Figs. 41 to 44, Plates 60,61, and 62. Fig. 41, Plate 60, is a general side elevation of the entire length of the machine. Fig. 42, Plate 61 , is a side elevation of one portion or compartment of the machine, to a larger scale and partly in section. Fig. 43, Plate 62, is a transverse section, and Fig. 44 an end elevation at the front end of the machine.

The bobbins A A, Fig. 41, Plate 60, are here all arranged in a horizontal line one behind another, in the axis of the revolving frame of the machine. The revolving frame is composed of a number of disc wheels C C, framed together by three long bolts D, Figs. 42 and 43 , passing through holes near the edges of the dises and through strong iron distance tubes with collars at each end, which are all turned accurately to one length. Eight discs C C, Fig. 41, are thus framed together by the three bolts, and separated by the distance tubes, forming seven compartments of the machine, each containing a bobbin of wire $A$. The last dise at the back end of the machine forms part of a three-speed cone pulley $\mathrm{E}$, by which the entire frame is made to revolve, being supported and steadied sideways at every alternate disc by the three rollers F, Fig. 43. The bobbin frames B B are centred in the revolving dises $\mathrm{C}$, and have a weight $\mathrm{G}$ suspended from their underside, sufficient to overcome the friction of the bearings and prevent the bobbin frames from revolving with the machine. 
The front end of each bobbin frame B, Fig. 42, Plate 61, has a hollow steel stud or " nipple" I, carefully bell-mouthed; and the back end has a solid stud H. Each stud works in a boss cast on the disc $\mathrm{C}$, having a clear hole right through the centre for the wire to pass through; and the boss on the front side of the disc has a large gap $J$, for the wire to pass out from the centre. The wire from each bobbin A, shown by the strong black line, is drawn off through the bell-mouthed stud I and the centre of the dise $C$, and is then taken round the leading pulley $\mathrm{K}$, Figs. 42 and 43 , which is fixed on the framing bolt $\mathrm{D}$ for the purpose of enabling the wire to clear the bobbin in the next compartment. The wires pass through holes in the dises $\mathrm{C}$ on either side of the framing bolts $\mathrm{D}$, as seen in Fig. 43 ; and on reaching the front compartment of the machine, all the six wires from the six bobbins A, Fig. 41, are led round three pairs of leading pulleys $\mathrm{K}$, and thence through the holes in the front disc, Fig. 44, through the laying plate L, Fig. 41, and over the laying top $M$. The laying plate $\mathrm{L}$ is attached to the front disc of the machine, and has a slot in it for each wire to pass through. The laying top $M$ fixed in front of the laying plate is simply a cast iron block with the required number of scores or grooves for the wires. The front bobbin N, Fig. 41, in the first compartment of the machine; carries a seventh wire to form the core for the six external wires, which is led off through the centre of the front disc and through a hole in the centre of the laying plate $L$ and laying top M. The tension or "temper" of each of the seven wires is regulated to the exact amount required by a friction break $O$ on the spindle of each bobbin, Fig. 43, Plate 62. The bearings of the spindle in the bobbin frame $B$ are provided with spring caps, to facilitate changing the bobbins.

The six wires are all brought together at a point immediately in front of the laying top M, Fig. 41, Plate 60, where they are all laid round the core by the revolution of the machine, the bobbins $\mathbf{A}$ remaining stationary with the exception of their unwinding motion as the wires are drawn off; each wire is thus laid into the strand free from twist in itself. The strand thus made passes between the nipping rollers $\mathrm{P}$, Fig. 44, which have a series of scores of different diameters to suit various sizes of strand or rope; the lower roller turns on 
a fixed stud, and the upper one on a weighted lever. The strand is then led half round the indicator sheave R, Fig. 41, which has a counter attached to indicate the number of yards or fathoms made. Thence it passes backwards alongside the machine to the draw-off wheels S S at the back end; these are $\mathbf{V}$ grooved wheels of equal diameter, round which the strand passes in a figure of 8 course, as seen in Fig. 41, being pressed tight into the groove of the second wheel by the tightening roller or jockey wheel $\mathrm{T}$, which prevents the strand from slipping from any accidental canse. The draw-off wheels $\mathrm{S}$ are driven from the driving pulley $\mathrm{E}$ by intermediate bevil gearing, with a change wheel by which the speed of the draw-off wheels is regulated in proportion to the speed of revolution of the machine, whereby the lay of the wires or pitch of the spiral in the strand is determined. The strand finally leaving the machine from the draw-off wheels is wound on a bobbin, ready to be placed in a second similar machine to be laid into rope. In this second machine the revolution of the laying apparatus is in the opposite direction while that of the draw-off wheels is in the same direction as in the first machine, in order to make the lay of the strands in the rope contrary to that of the wires in each strand. From the second machine the rope is coiled on a reel, or in case of its being a long length it is sometimes coiled down direct into railway trucks \&c. for transportation.

In this machine, instead of the bobbins and bobbin frames, which sometimes contain half a ton weight each, being carried round the common centre of the machine, sometimes describing a circle of 15 feet diameter, and also rotating on the axes of the bobbin frames once for every lay in the rope, the same result is attained wilhout any motion being given to the bobbin frames. This is an important advantage, because in course of working some of the bobbins are full while others are nearly empty, and in the case of the old machinery a great strain is thereby thrown on the parts of the machine from the variation in weight; while in the construction just described the equilibrium of the machine is never disturbed. In addition to this, great regularity of lay results from the wire being free to unwind, and from the absence of the extra tension that was necessary to prevent the wire being disturbed when rapidly carried round in the old machine. The stationary position of 
the bobbins enables the workman to see what is going on, and no entanglement of the wire takes place as is frequently the case in other machines.

About 35,000 miles of the covering strands of the Atlantic telegraph cable were made in this machine; and likewise about 14,000 miles of the hemp-covered strands of the Toulon and Algiers cable. It is also extensively used in the manufacture of wire ropes.

Steel wires are now extensively used in the manufacture of wire ropes, being found to possess twice the strength of the best charcoal iron wire; while the skin of the wire is of such remarkable hardness as to resist a very great amount of friction, and the wire has a toughness equal to that of copper. A compound hemp rope is also now made by inserting a wire in the centre of each yarn, and making these yarns up as an ordinary liemp rope.

A number of specimens of hemp and wire ropes were exhibited, illustrating the several constructions described in the paper; and also working models of some of the rope making machines, lent for the occasion from the South Kensington Museum. A working model was also exhibited and shown in action of Smith's wire rope machine described in the paper.

Mr. SHeLley thought it was highly important that the reasons should be ascertained which led to hand making being reverted to in the manufacture of hemp ropes, in place of the beautiful machinery invented for the purpose by Capt. Huddart and used for some time in Deptford dockyard; he had been unable himself to ascertain why the 
machinery had been given up, or what were the exact defects experienced with it. The basis of all the machines, both for hemp and wire ropes, seemed to be Mr. Cartwright's cordelier invented at the end of the last century.

Mr. B. FotmergitL believed that one reason of the want of success of the machines for the manufacture of hemp ropes was a defect in the preparation of the material by the machinery, which did not produce a uniform thickness of thread; and the want of uniformity of thread resulted in unevenness of the strands made from the yarns, and consequent unevenness in the ropes themselves. Also wherever there was a small part in the thread, the twist all ran into that particular place, and the thicker parts of the thread did not get twisted enough; so that when a strain came upon the rope, the thicker parts of the threads gave way and were drawn out and the strain was all left to be borne by the smaller parts, and breakage was the consequence. Another defect in the machines was that no provision was made for laying exactly the same length of yarn upon each bobbin : this might readily be done by a measuring apparatus such as was ordinarily applied in cotton machinery, and then the bobbins would all be empty at the same time, and there would not be a heavy full bobbin on one side of the revolving frame of the machine and a light empty one on the other. In some hemp rope machines also there had been a defect in the arrangement for giving uniform motion to the twisting of the different strands when they were being laid into the rope. He thought the paper that had been read was one of a very interesting and instructive character : with regard to the manufacture of wire rope, he believed the hand method which formed the basis of the manufacture had its origin in the Hartz mountains.

Mr. A. Smith remarked that in wire rope machines the inequality of weight arising from full and empty bobbins on opposite sides of the stranding machines was inevitable in the previous constructions of machines; for the wire was necessarily supplied to the machines in boblins which would not contain the whole length of wire required for the entire strand, and it wonld be very unwise to let all the bobbins empty at once and all the joints come at one part of the strand. The bobbins therefore inevitably emptied at different times in the stranding 
machines; but in the rope machines they all emptied simultaneously, since each bobbin contained the exact length of strand required for the whole length of rope.

Mr. Shelley enquired whether the defects that had been mentioned in the manufacture of hemp ropes had been overcome in the machine shown in the American department of the Exhibition, where the yarns were taken in at one end and twisted into strands, and the strands were then laid into a rope which came out at the other end of the machine. This machine was now at work, making ropes of half an inch diameter.

Mr. B. Fothergill said the defects he had mentioned were not entirely overcome in the machine referred to; but the main defects lay in the preparation of the material before it was spun into yarns. In the treatment of flax or cotton the raw material was first got into a slivered form, and was then passed through a series of rollers, taking care not to destroy the fibres, but to draw and lay them parallel side by side; and in order to get uniformity of thread in spinning, the fibres so drawn out were then doubled again and again as many as twelve or thirteen times in the case of fine cotton spinning. Without this doubling it was impossible to obtain uniformity in the thread, and the defect that he had referred to in the manufacture of the threads for hemp ropes arose from the want of a sufficient number of doublings, so that in spinning the yarns there was a want of uniformity in the thickness; and in forming the strands these yarus were only congregated together, whether thick or thin, in a sufficient number for the required size of strand. The only approach to doubling was the twisting together of the yarns into the strand; but the doubling ought to take place in the raw material, so as to secure a uniform thickness of thread, and then the ropes would no doubt stand a much greater tension.

Mr. F. J. Bramwell remarked that in 1853 he had seen some hemp rope machinery at the Boston dockyard in America, where there was an arrangement in the preparing machine to equalise the amount of material taken in, by producing a retardation to prevent thick parts occurring in the thread; this was found to work well, and he had thought the difficulty on that score had been thereby overcome. 
Mr. J. Fuetcher observed that he had lately seen some new machinery which was now being tried at Chatham dockyard for the purpose of ascertaining the difference of strength and pliability between hand and machine-made rope, made from the same hemp: and he understood the result already arrived at was that the machine-made rope was superior to the hand-made. In the manufacture of the machine-made rope the doubling system was adopted: six slivers of hemp were passed together through rollers, and two of these rollings were twisted together and spun into one small thread, and a strand was composed of a number of these threads twisted together.

The Chatrman enquired whether the comparison of the hand and machine-made ropes was made weight for weight: and also what was the relative quantity of tar that was held by each construction of rope.

Mr. J. Fletcher replied that the comparison of the ropes was made weight for weight and girth for girth; but the ropes were dry and no tar was used in them. He was not able to state the exact results arrived at with regard to the superiority of the machine-made ropes, but understood the general result was decidedly in their favour.

Mr. P. HAGGIE remarked that he had found in the manufacture of hemp ropes that in the preparation of the hemp the less it was passed through the rollers and doubled the better, if only the fibres were got something like straight and parallel : for after about the third time of doubling and passing through the rolling machine the gummy part of the fibre seemed to be destroyed by further manipulation, and although the fibres might be got more parallel, the yarn spun from the hemp was not so strong as when the hemp underwent less preparation. At his own works they had experimented a good deal upon the difference between hand work and machine work, and found that machine-made rope was about 25 per cent. stronger than hand-made rope of the same girth. The government test for yarn was 8 stone or $1 \mathrm{cwt}$. for a single yarn of the common size No. 18 ; but out of the same hemp machine-made yarn of the same size would bear from 12 to 18 stone; and he hoped they would ultimately be able to ensure a definite strength in all ropes of a given size and material. In 
collieries, where machinery had often to be lowered into the pits and men's lives were dependent on the strength of the rope, it was particularly important to be able to rely on a certain definite strength throughout the entire rope.

Mr. B. Foтhenall observed that, with regard to the preparation of the hemp fibres, the doubling of the material was perhaps a point of less importance than that care should be taken to aroid breaking the fibres in the process of laying them side by side: if the doubling were too frequent or if the several pairs of rollers were not at the right distance apart from one another, the fibre would be broken. The importance of treating the fibre in the right way to begin with might be understood from the fact that Heilmann's combing machine, which combed the fibres and laid them parallel without breaking them, had in the course of only five or six years become extensively applied to cotton, wool, and flax; and in the case of cotton a better yarn was produced by the use of this machine out of cotton that was $6 d$. or $7 d$. per $\mathrm{lb}$. cheaper than that required under the old method of carding. A series of these machines also selected the fibres according to their length, and he had known as many as fourteen different lengths of fibres got out of one sample of material; of these the longest could then be taken for the best class of work, and the shorter lengths for inferior work. If care were taken that the fibres thus combed and laid parallel should not be broken in the after treatment of the material, so as to maintain their length and uniformity, the yarns spun from such a sliver would be five or six times as strong as under the old mode of preparing the fibres.

Mr. E. A. Cowper remarked that at Portsmouth dockyard which he had lately visited scarcely any machinery was used for rope making, steam power being employed only to turn the spindles of the ordinary hand machines. There appeared to be a strong prejudice against machine-made hemp rope, which was said to be deficient in strength. He was glad to learn however that at Chatham attention was now being paid to the subject, for he was satisfied that hemp ropes could be thoronghly well made by machinery, and that more strength could be got with hemp rope properly made by machinery than with hand-made rope of the same size. 
The Chairman enquired what was the reason why Capt. Huddart's machinery was discarded at the dockyard, if other manufacturers had found the machine-made ropes could be made so superior to hand work ; and whether the machinery was still in use at any other of the dockyards.

Mr. E. A. Cowper replied that Capt. Huddart's machinery was used for upwards of forty years at the Deptford dockyard, but at the end of that time the government pulled it down and it was bought by Huddart's firm, and it was not now used in any of the government dockyards : but he had not been able to ascertain the reason why it was given up there, when the use of machinery had been found so advantageous elsewhere.

Mr. P. HaGGIE said that some years ago his works were visited by some government officials for the purpose of testing some government hand-made ropes with his machinery; and he had since learnt that they found the manufacture of the hemp ropes as carried on by machinery at the works was much superior to the old plan of hand work in the government yards; but there the matter was allowed to drop, and the question had been shelved ever since. With regard to the plan of repeated rolling with a succession of rollers in preparing the hemp for spinning, he believed that method would not apply to long fibres such as those of hemp, the ordinary length of which was from 5 to 6 feet, and therefore there was no other way of dealing with the hemp but that which they adopted of getting the fibres as nearly straight as possible, with the least possible drawing, so as to get the greatest amount of strength out of the hemp.

Mr. E. A. Cowper observed that in passing the hemp through the drawing rollers the distance between the successive pairs of rollers must of course be arranged according to the length of the fibres, in order that the fibres might not be broken in the machine: and the same precaution had to be observed, whatever was the material undergoing preparation.

Mr. F. JENKIN remarked that in the new horizontal wire rope machine now described the wire appeared to undergo a considerable amount of bending in its course from the bobbin to the laying plate, each wire being bent on all sides successively during each revolution of 
the machine in passing through the hollow nipple in the centre of the revolving disc, becoming thus crimped into a wary form with a length of wave corresponding to the length of lay of the strand. This might not be of any importance in the case of small wires, but in large wires he thought it would be a serious defect to bend the wire in this manner; and he enquired whether any of the machines had been applied to laying large wire into strands.

Mr. A. Sмrth explained that the bending of the wire previous to its arrival at the point of laying was not peculiar to the new machine, but was common to the previous vertical machines also: it was only more apparent in the horizontal machine, because the length of the machine was there so great that it was desirable to shorten it as much as practicable by increasing the angle of bending. But so long as the bending of the wire between the bobbin and the point of laying was less than the bending it received in being laid into the strand, no harm was done, whether the wire were thick or thin : had it been of importance to avoid bending the wire more than necessary, the machine might have been lengthened to the required extent for the purpose. The new machine had been applied to large wire as thick as No. 4 wire-gauge or 0.240 inch thick, without any injury to the wire; and it had been adopted and successfully employed by Messrs. Glass Elliot and Co., for laying on the covering wires for protecting the shore ends of telegraph cables.

Mr. T. Sxowdor asked whether the wire was bent so much as to cause it to scale.

Mr. A. Surru replied that it was never bent to such an extent as to throw off a scale.

Mr. J. Fletoher remarked that no harm could be done to the wire if the bending in the machine were less than that which it had upon the bobbin.

Mr. P. Hagais observed that the strength of steel wire had been stated in the paper to be twice that of the best charcoal iron wire, but his own experience was that the best steel wire was only 50 per cent. stronger than charcoal iron wire, while the common run of steel wire was not more than 10 per cent. stronger than iron, and some steel wire was not even equal in strength to iron. It was also a question 
of great importance how to prevent steel wire as well as iron wire from becoming brittle in work: the wire seemed to change its character and become crystallised by the friction the rope was exposed to in passing over a series of pulleys, and in a few months' time the rope became quite brittle. The process of crystallisation was slower in iron wire than in such steel wire as had hitherto been made for the purpose of wire ropes.

The Chatrman enquired what had been found to be the actual strength of ropes made of charcoal iron wire.

Mr. P. HaGgie replied that he had lately tested an iron wire rope of about $1 \frac{1}{10}$ inch diameter, which had been in use three months, and it bore $18 \frac{1}{2}$ tons before breaking; it was a "formed" rope of six strands, each strand being "formed" of 19 wires twisted together, of No. 16 wire-gauge or 0.065 inch thickness, so that the whole rope contained 114 wires or 0.378 square inch section of iron, giving a breaking strength of 50 tons per square inch. This rope had been damaged by an accident, and was tested for the purpose of ascertaining its strength in the uninjured part.

Mr. ShezLey asked what size of hemp rope would be required to bear the same weight as the wire rope, and what would be the respective weights of the two ropes.

Mr. P. Hagate replied that an 8 inch hemp rope would be required to bear the same load of $18 \frac{1}{2}$ tons before breaking, that is a hemp rope of 8 inches circumference or rather more than $2 \frac{1}{2}$ inches diameter, or else a flat hemp rope $4 \frac{1}{2}$ inches broad composed of four smaller ropes: the last hemp rope that he tested of about that size, $8 \frac{1}{2}$ inches circumference, broke at 28 tons, but that was an extreme case. The weight of the hemp rope was about $1 \frac{1}{2}$ times that of the wire rope of the same total strength; for the 8 inch hemp rope weighed $16 \mathrm{lbs}$. per fathom, while the wire rope was $10 \mathrm{lbs}$. per fathom.

Mr. A. Sмiтn said that as regarded the relative strength of steel and iron wire the statement in the paper was founded upon a number of experiments that he had witnessed, from which it appeared that $500 \mathrm{lbs}$. was a very fair breaking test for charcoal iron wire of No. 14 wire-gauge or 0.085 inch thickness, amounting to 40 tons per square inch section of metal; while he had seen steel wires of the same gauge, 
of a superior manufacture, bear 1000 and even $1100 \mathrm{lbs}$., or 80 to 90 tons per square inch. He thought it was generally admitted that ordinary steel wire made for wire ropes would bear nearly double the strain of iron wire of the same gauge, the generally received proportion being 7 to 4 . Fowler's steam plough afforded a good instance in which fine steel wire ropes were used with advantage, from their superior strength and lightness as compared with iron wire ropes: and he had also heard of a valuable application of steel wire rope in France for transmitting power to half a mile distance; in this case the ropes used were very light, only about 5-16ths or 3-8ths inch diameter, and were driven at a very high velocity.

Mr. E. A. Cowper observed that some experiments which he had made on the strength of Webster and Horsfall's hard steel music wire gave the ordinary breaking strength at about 85 tons per square inch. In one case of very hard wire the breaking weight was found to be as high as 130 tons per square inch, but this wire was rather too hard for use.

Mr. P. HAGgie said the highest result he had obtained with steel wire rope was in a rope of $3 \frac{1}{2}$ inches girth which he had just tested, made of the best quality of wire, which broke at $35 \frac{1}{2}$ tons ; while an iron wire rope of the same size would break at about $22 \frac{1}{2}$ tons. But this seemed an exceptional case, for in other steel wire ropes which he had tried of the same size the highest breaking strain was only $22 \frac{1}{2}$ tons : and he had found a single bundle of steel wire contain so many varieties of temper that the objections against the use of steel wire ropes appeared more serious than those which had been urged against machine-made hemp ropes from irregularity in the spinning of the yarns.

The Chatrmas enquired what would be the strength of a hemp rope of the same size, and what was the relative durability and cost of hemp and wire ropes of the same strength.

Mr. P. Haggie replied that a hemp rope of $3 \frac{1}{2}$ inches girth would not bear more than about $3 \frac{1}{2}$ or 4 tons. But in comparing hemp and wire ropes of the same strength he believed that if the same attention were bestowed upon the hemp rope as upon a wire rope the hemp rope would be found more economical in durability as well as in first cost, 
provided the depth of the pit were not extreme. Beyond a certain limit indeed a hemp rope used for winding in a pit would kill itself; that is the great weight of the rope itself hanging down the pit and the consequent continued stretching every time it was lowered would eventually cause it to become almost rotten, and it would then give way.

The Chairman hoped Mr. Haggie would give the results of his experiments on the strength of hemp and wire ropes in the form of a paper at a future meeting of the Institution. He proposed a vote of thanks, which was passed, to Mr. Shelley and also to Mr. Smith, for the information communicated in the paper that had been read, and the numerous interesting models and specimens by which it was illustrated.

The Meeting was then adjourned to the following day. In the afternoon the Members visited the Government Small Arms Factory at Enfield. 
The Adjourned Meetina of the Members was held in the Lecture Theatre of the Royal Institution, Albemarle Street, London, on Thursday, 3rd July, 1862; Sir William G. Armstrong, President, in the Chair.

The following paper, communicated through Mr. Charles P. B. Shelley of London, was read :- 
ROPE MANUFACTURE.

Hand Spinning Machine for Hemp Rope.

Fig. 1. Front Elevation.

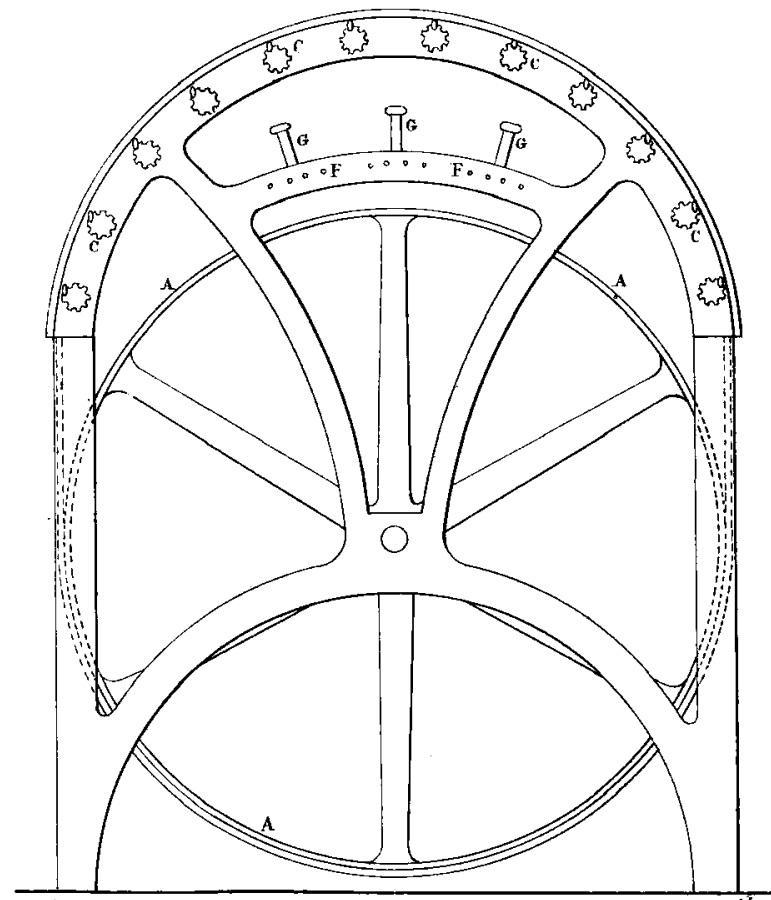

Fig. 2. Side Elevation.
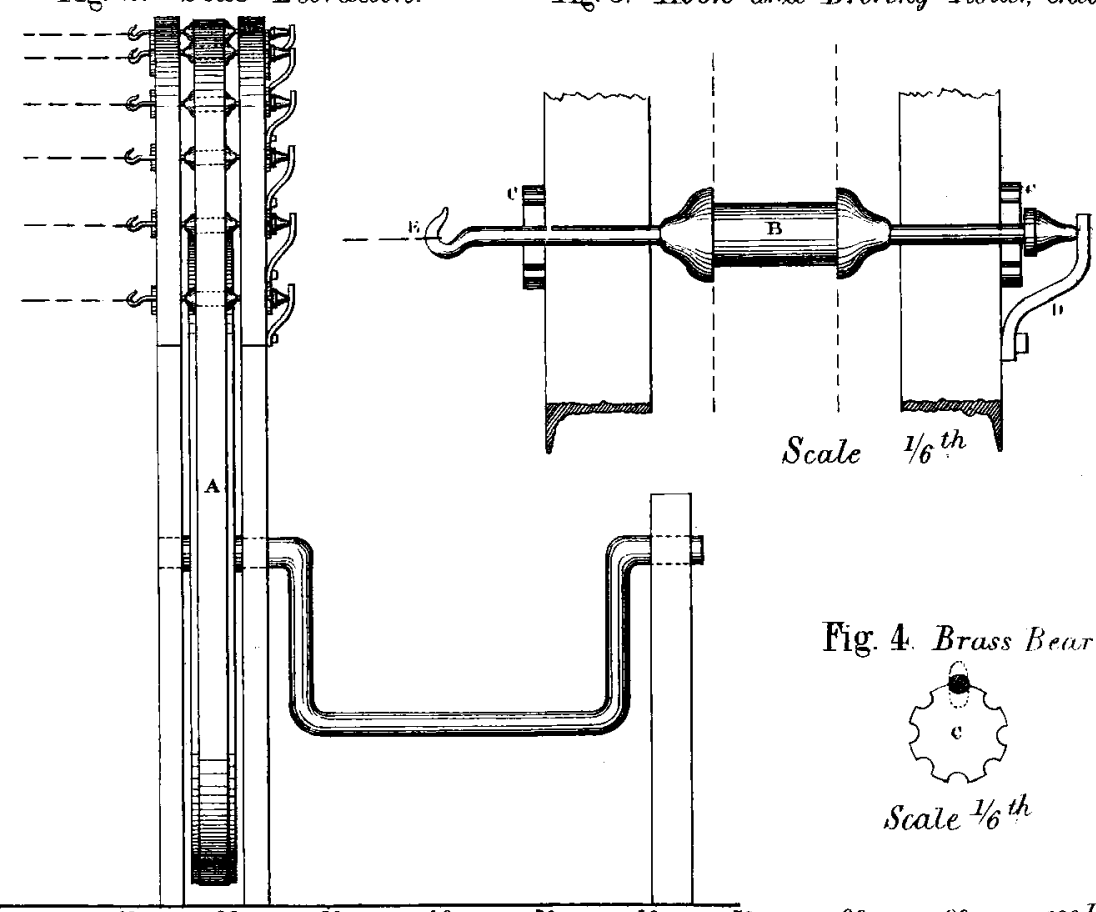

Fig. 4. Brass Beurung.

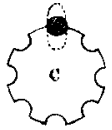

Scale ${ }^{1 / 6^{t h}}$

Fig. 3. Hook and Driving Roller, enlarged. 
Fig.5. Half Front Elevation

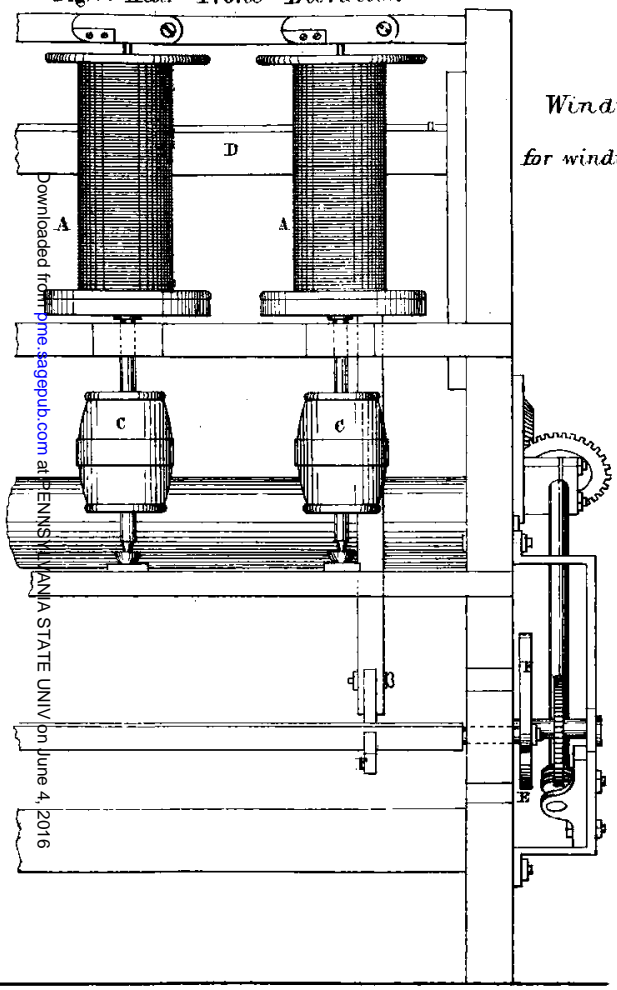

(Proceedings Inst. N. E. 1862 Page 170.) \&cale $1 / 66^{\text {th }}$

\section{ROPE MANUFACTURE.}

Ptate 47.
Fig.6. End Elevation.

Machine

upon bobbires.
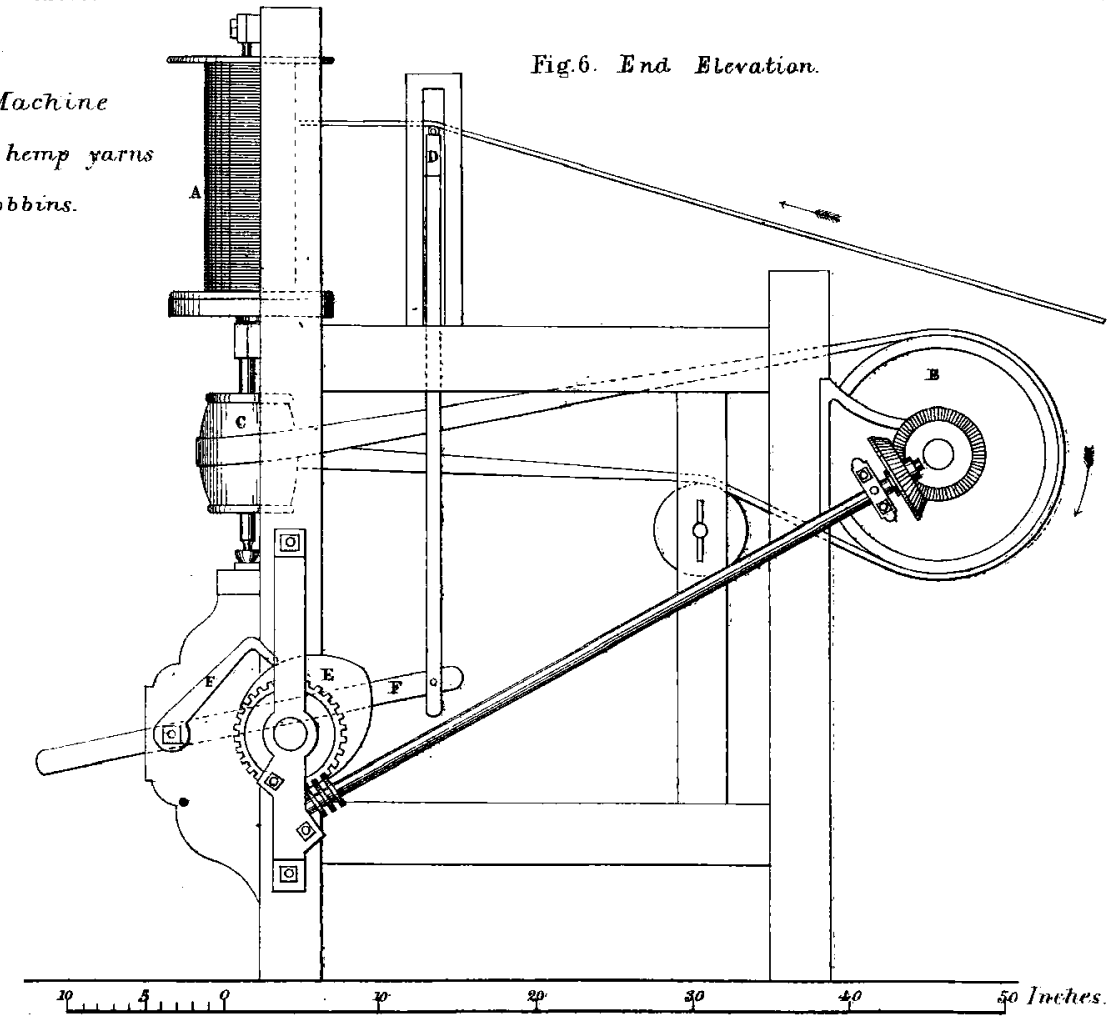
Fig. 7. Forming Machine

for "forming" the strands for Hemp Rope.
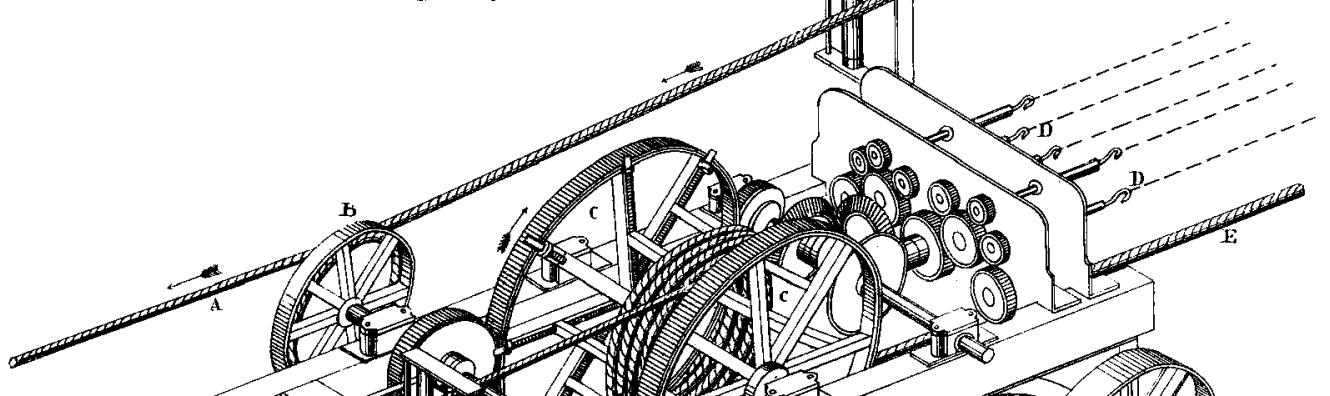

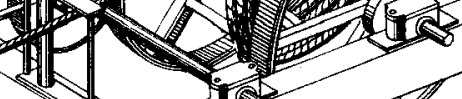
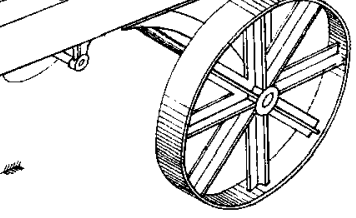

Scale $1 / 32^{\text {nd }}$ 
Fig.8. Upper End Laying Machine for "laying" the strunds of Hemp Rope
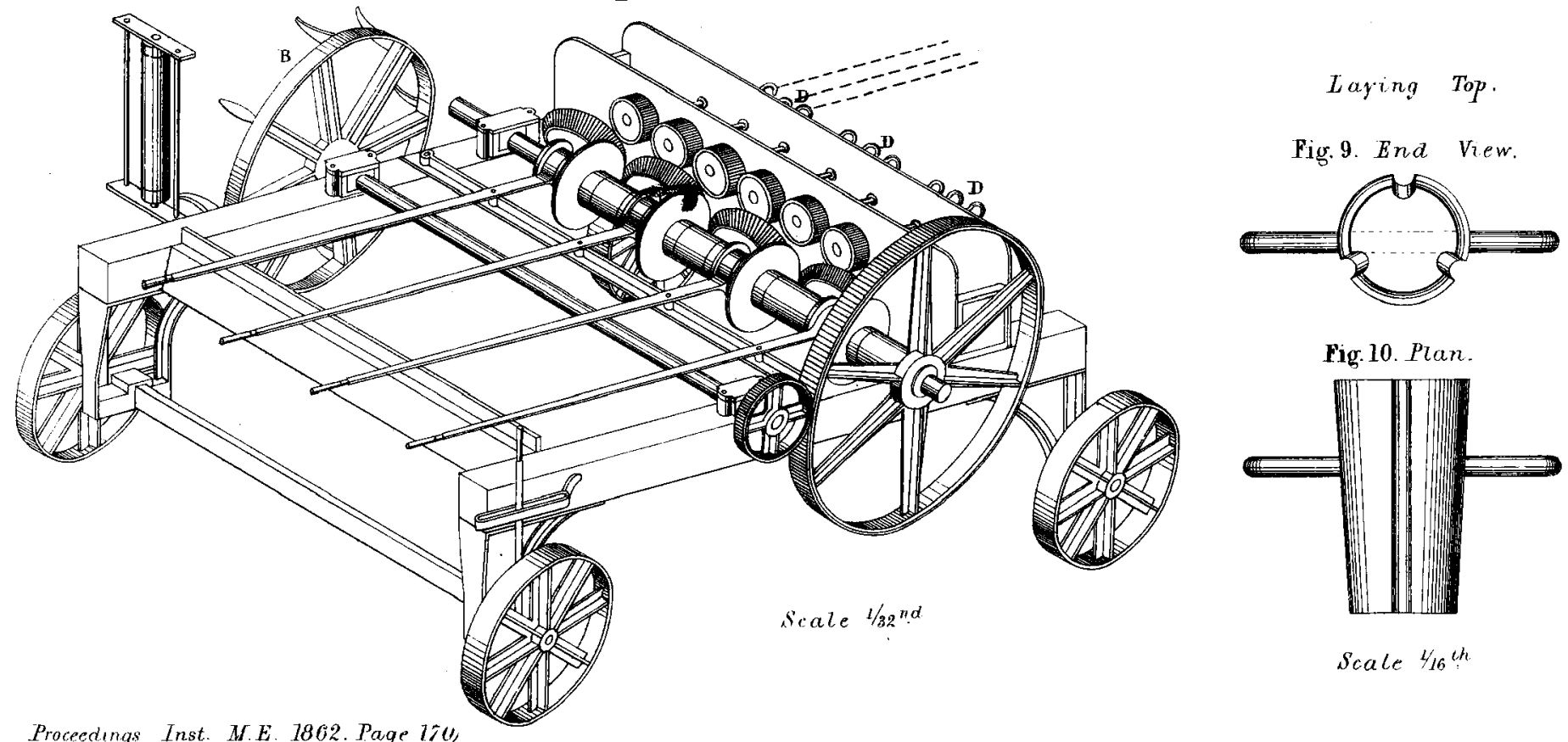

Proceedings Inst. M.E. 1862. Page lTU

Downloaded from pme.sagepub.com at PENNSYLVANIA STATE UNIV on June 4, 2016 
ROPE MANUFACTURE.

Fig. 11. Lower End Laying Machine

for "laying" the strands of Hemp Rope

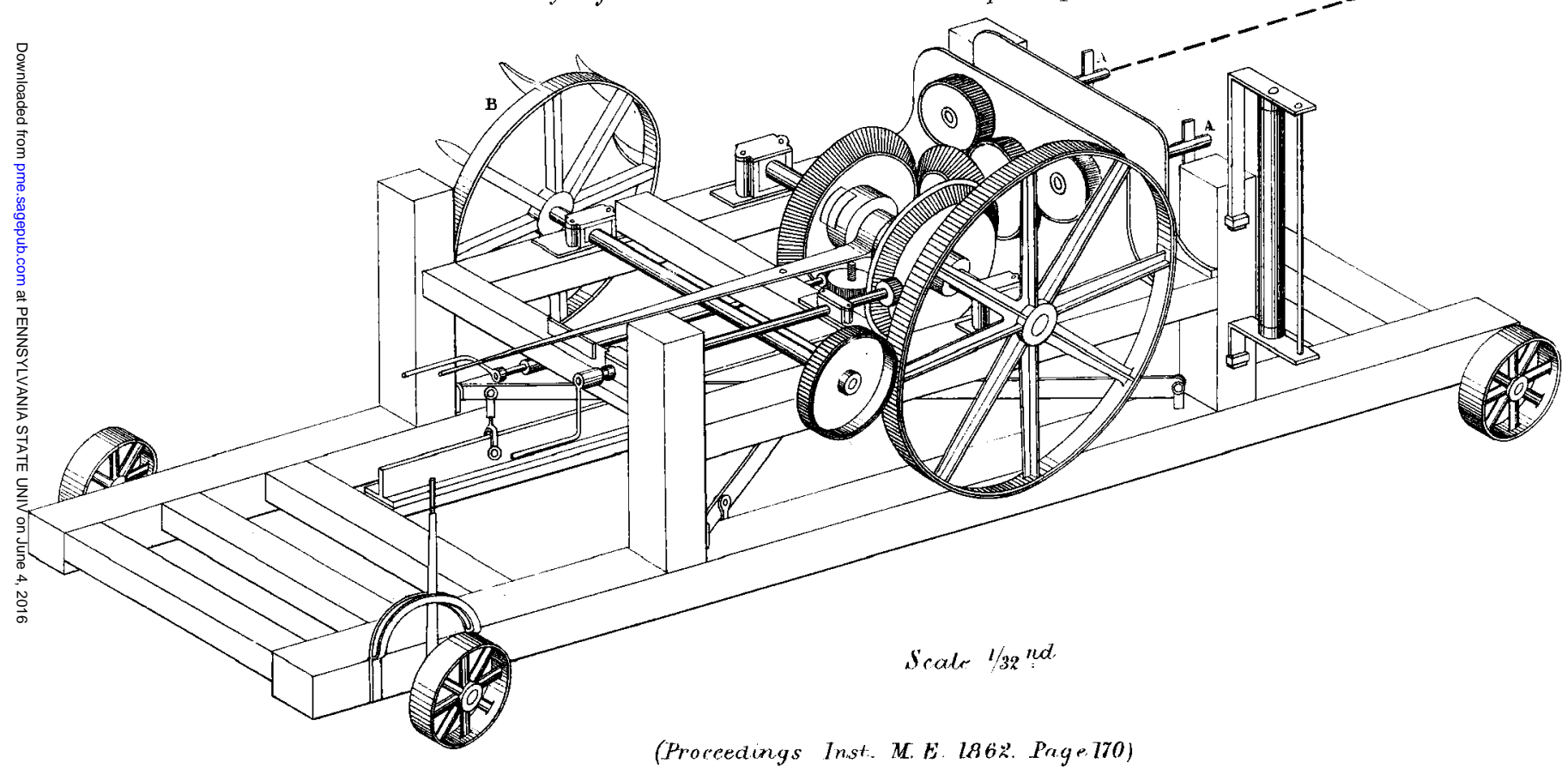




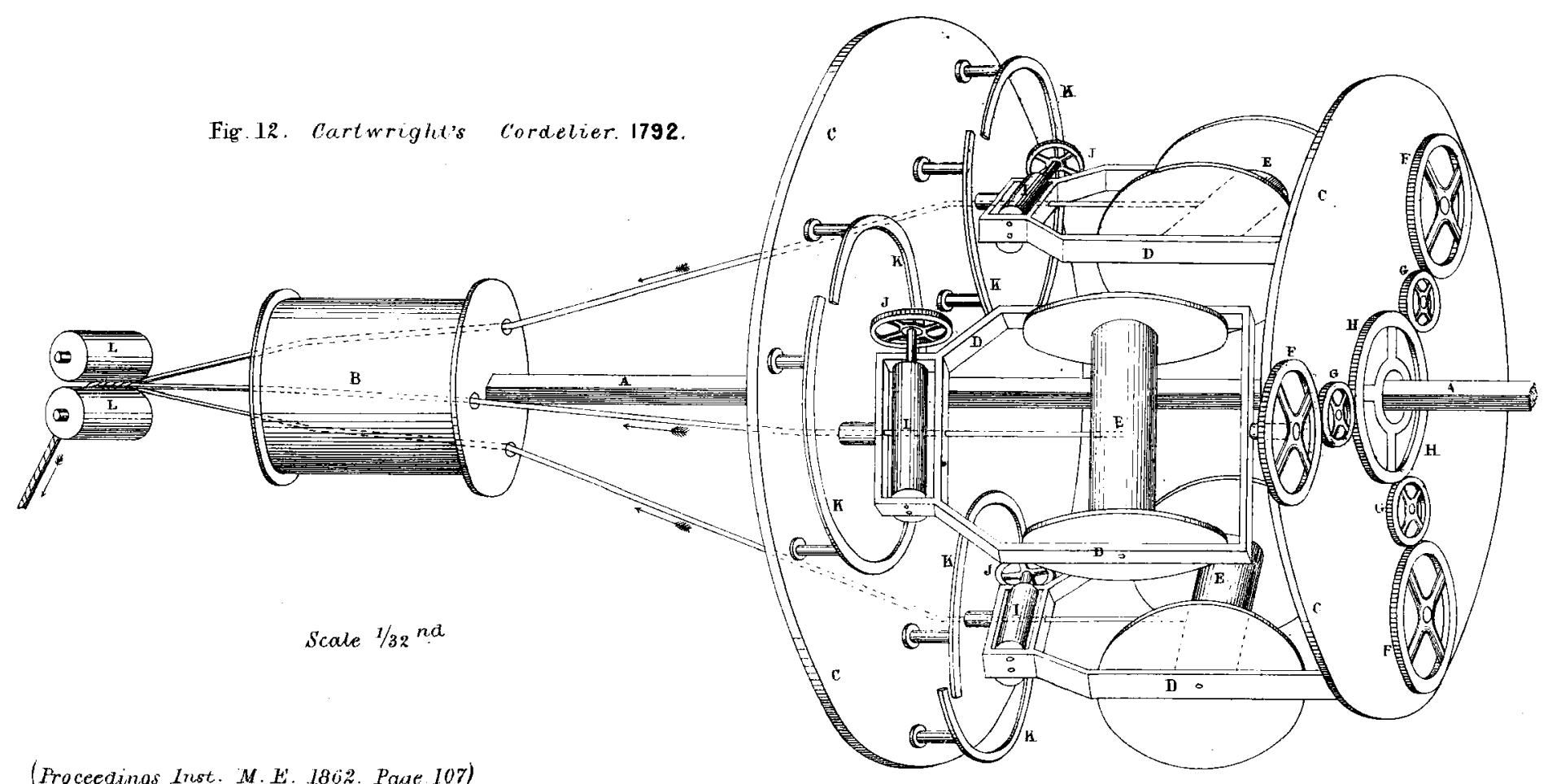




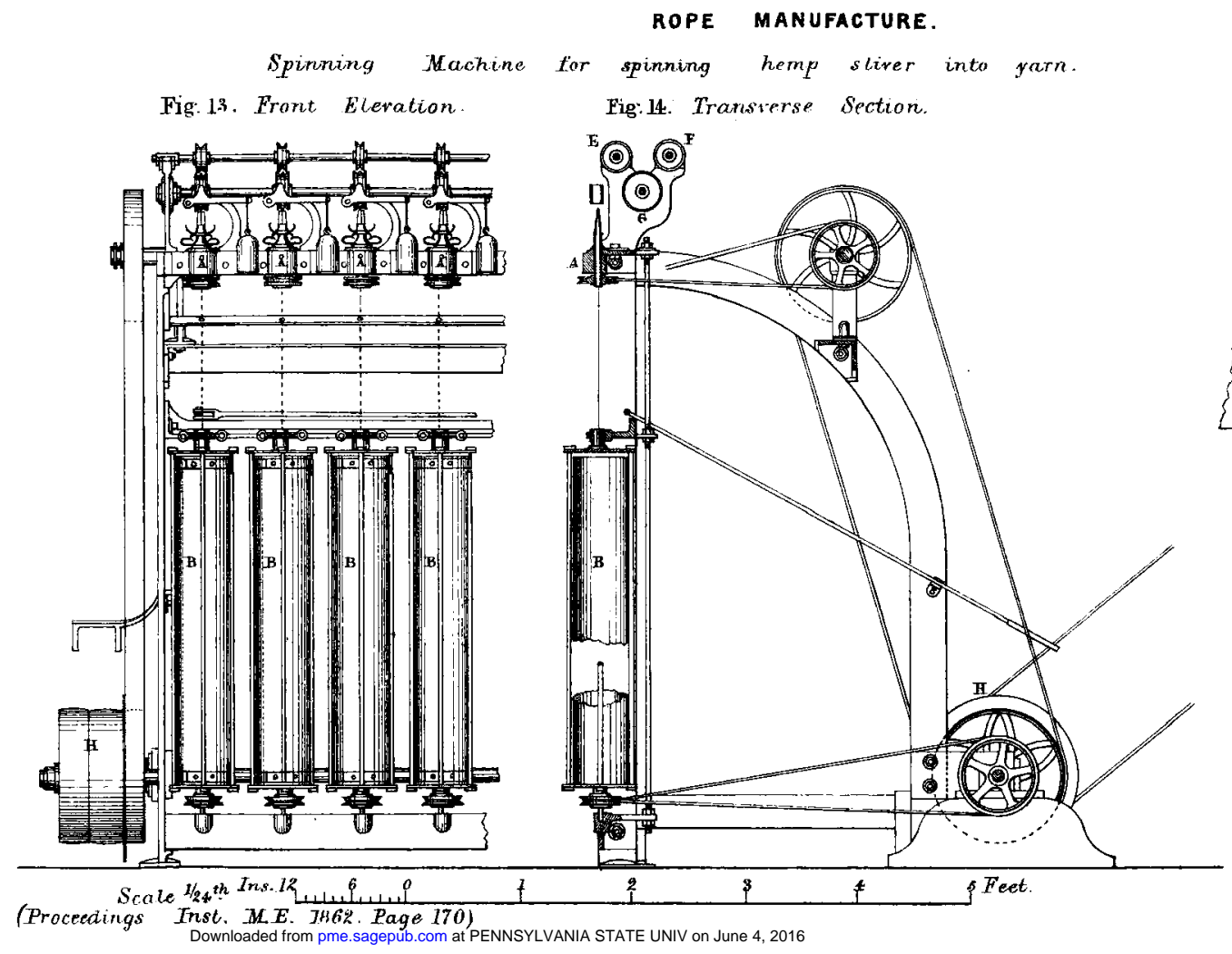

Fig.15. Detail of Spinning Tabe and

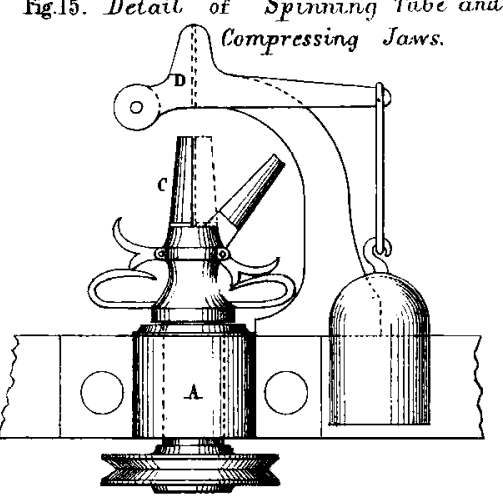

Fig. 10. Plan of clip.

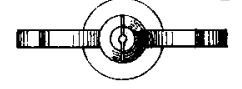

Tig.17. Ptan of Compressing Jaws.

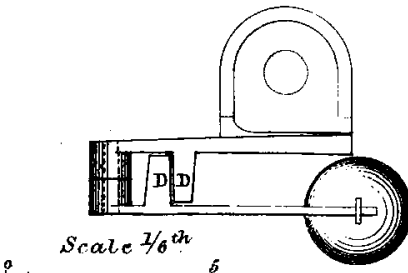


Fig.18. Plan of "Registering" Machtne

into a strana

and

winding

the strand

on a drum.

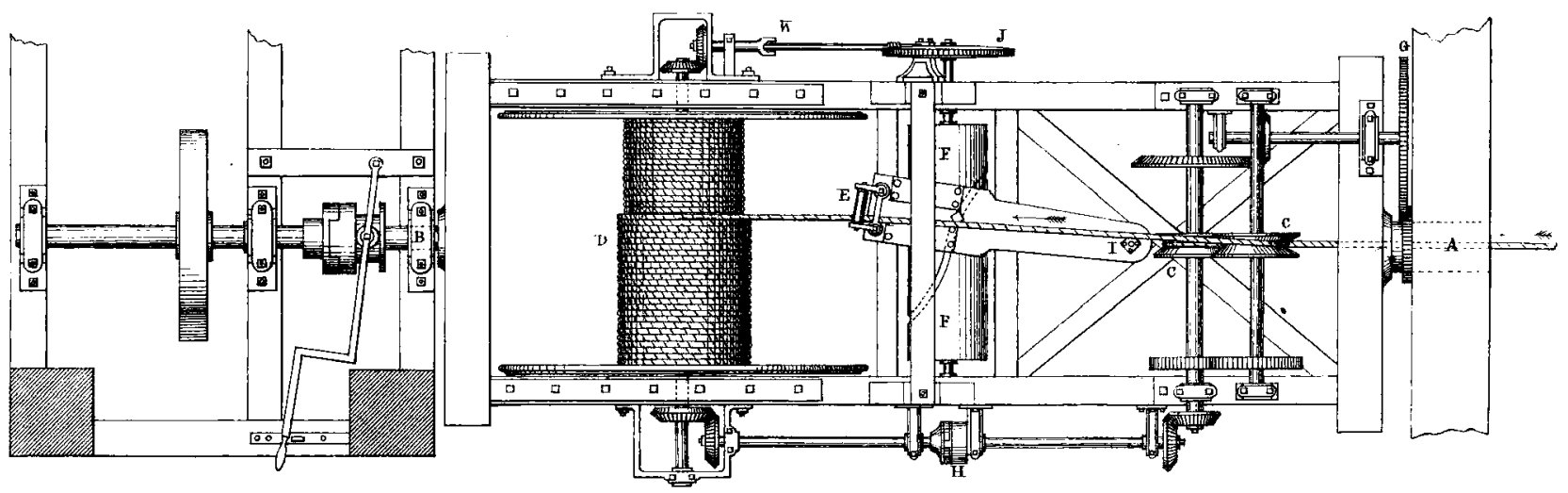

Scale $1 / 32$ na. Ins. $12 \quad 6 \quad 0$

5 1o Feet

(Proceedings Inst. M.E. 1862. Hage 170) 


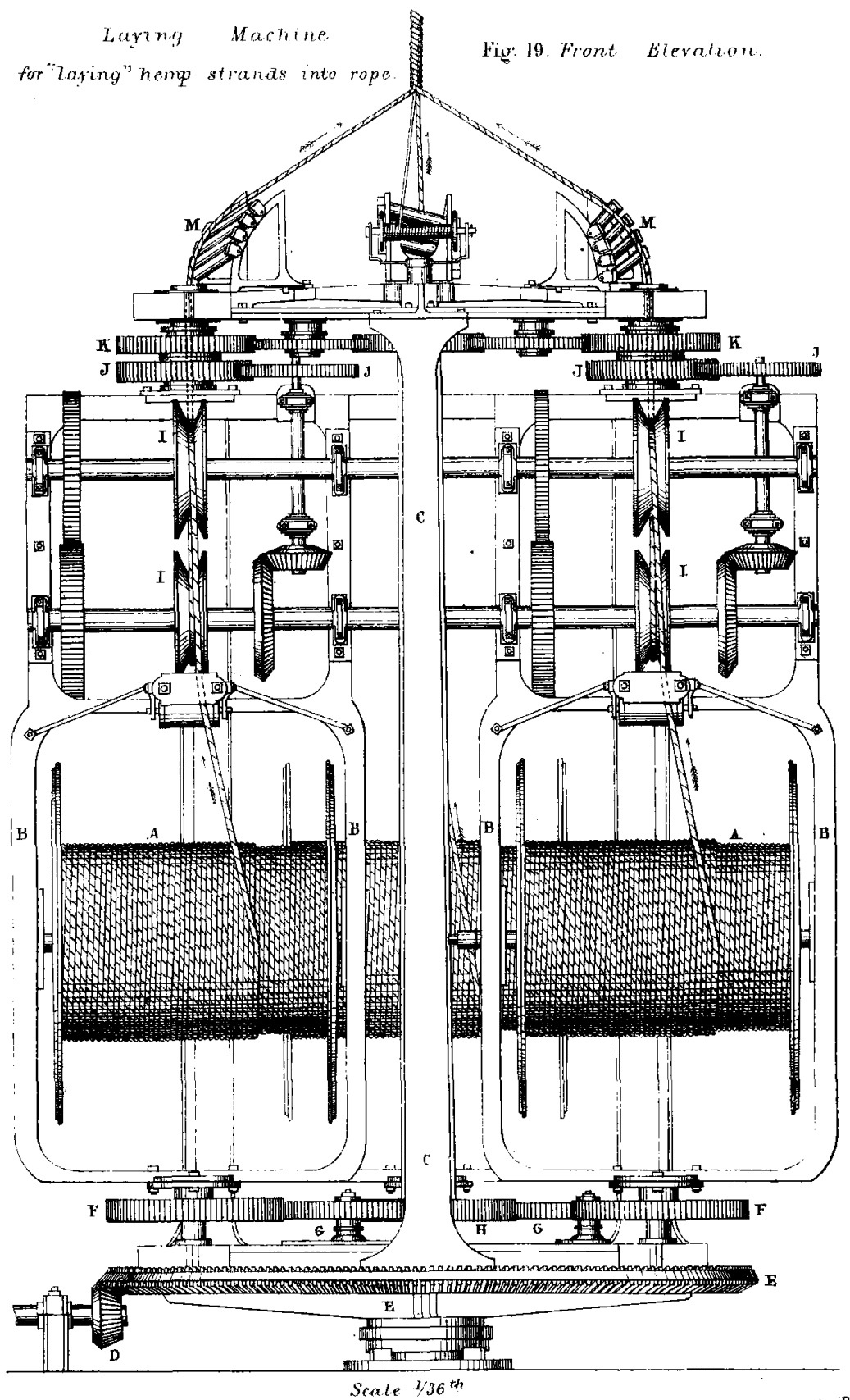

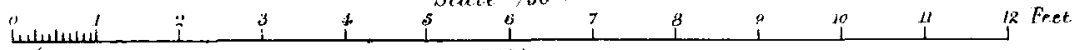

(Proceelings Inst M.E 1862. Pagr 770)

Downloaded from pme.sagepub.com at PENNSYLVANIA STATE UNIV on June 4, 2016
} 
ROPE MANUFACTURE.

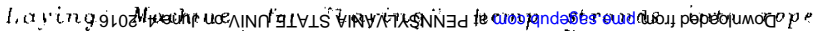

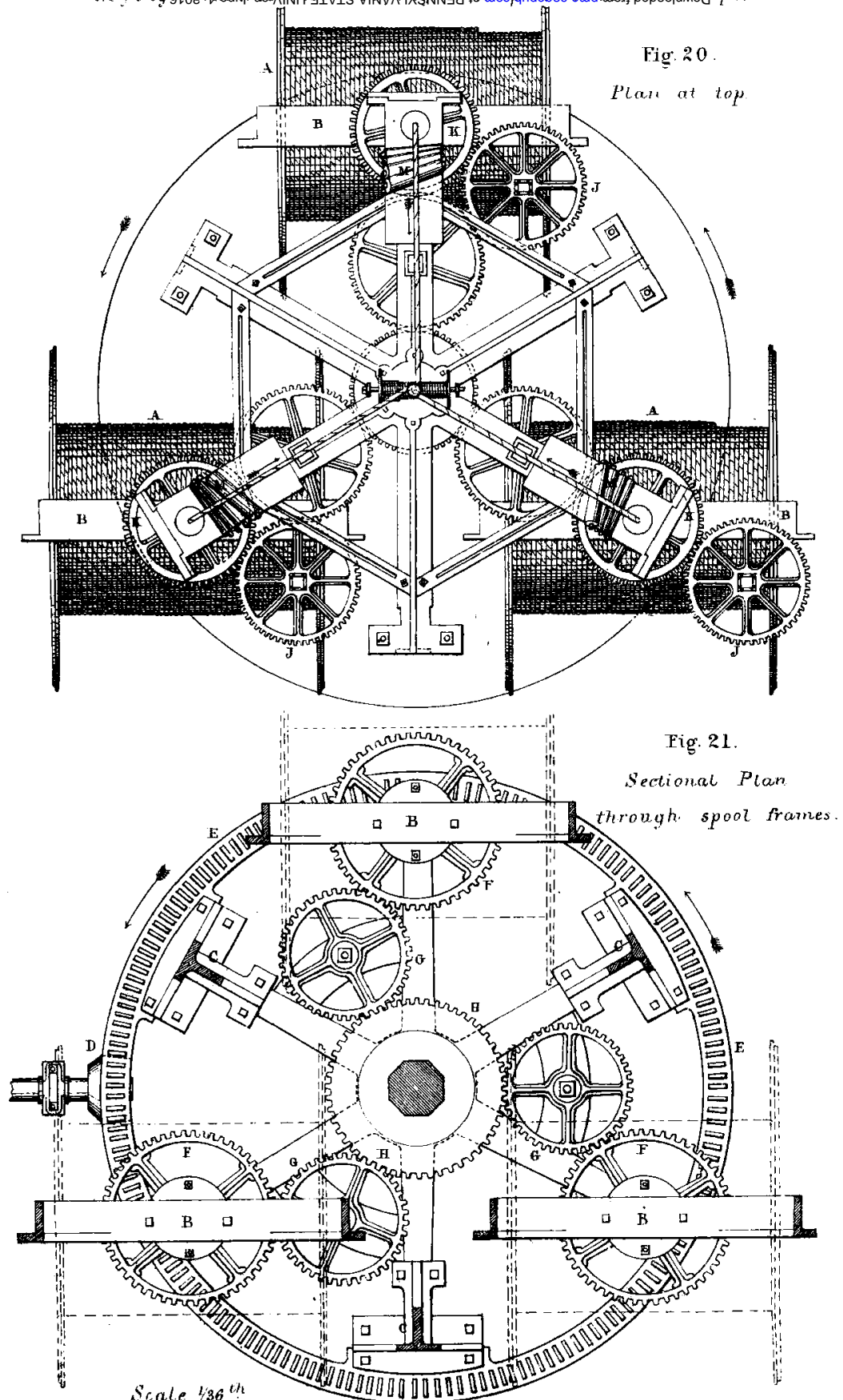

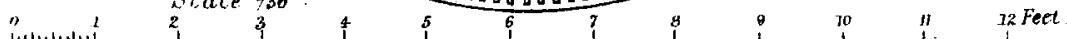
(Procedtings List. M.E. 1862. Fage 170) 


\section{ROPE MANUFACTURE,}

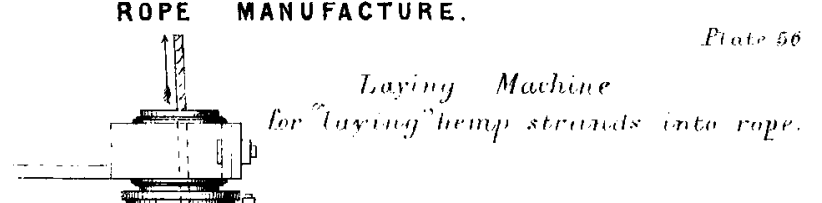

fig. 22

Side Elevalion of spont frame

entaryed.

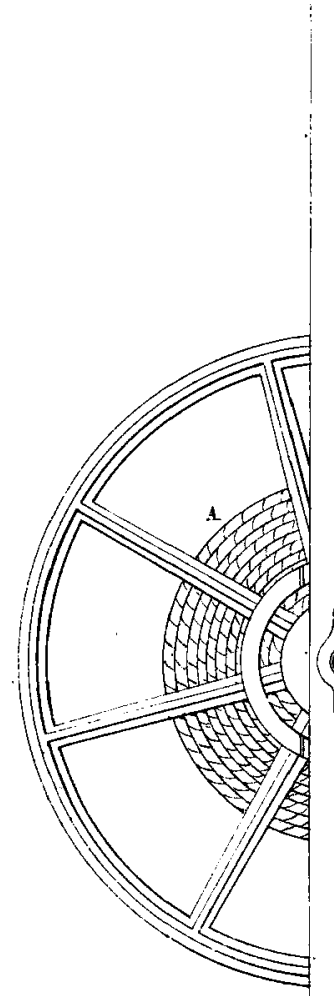

B

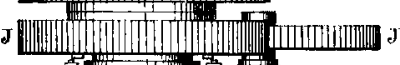

Fig. 23
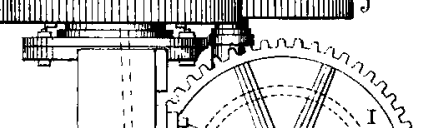

,
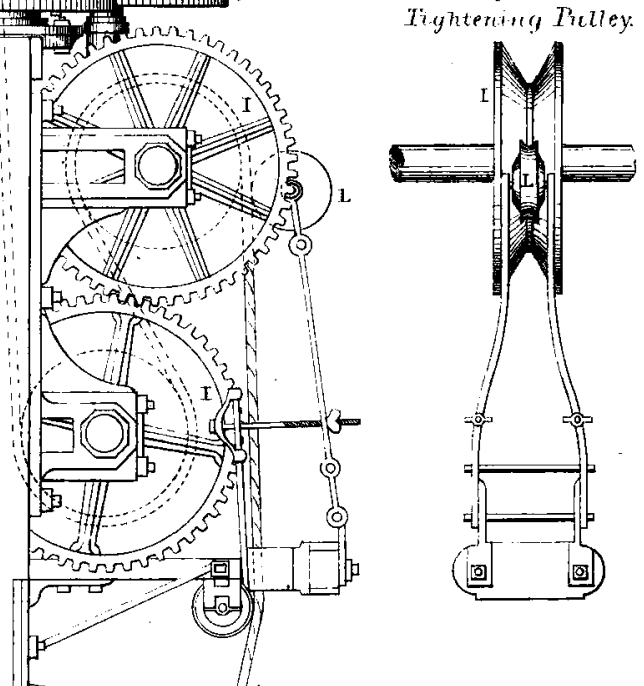

[]

이

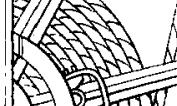

(0)

回!

0]
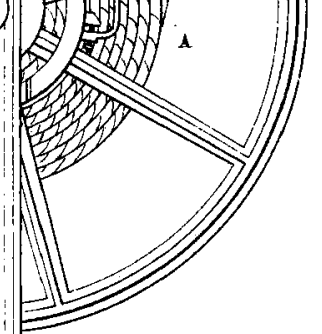

F . 
Wire Ropes.

Fig.24. Freiburg Suspension Bridge Cable. 1835.

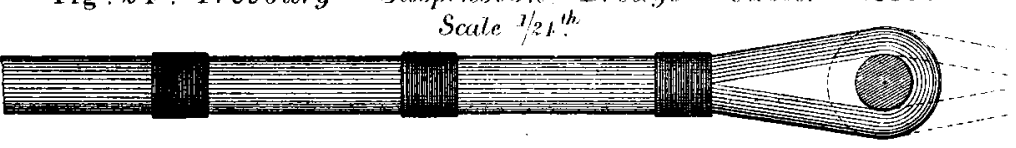

Fig.25. "Selvagee" Wire Rope: $1835 . \quad$ Fig. 26.

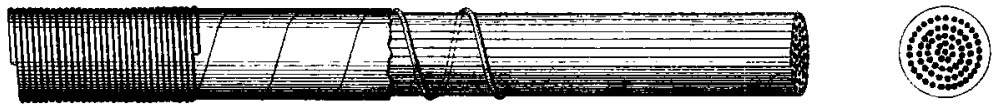

Fig.27. "Formed" Wire Rope.

1837.

Fig. 28 .
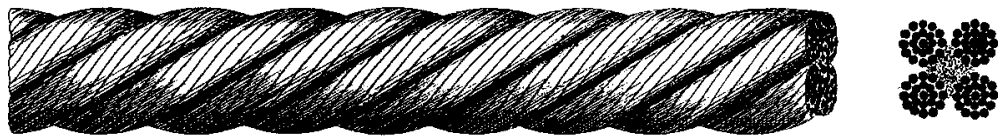

Fig. 29. First Flat Wire Rope. 1836

Fig. 30 .
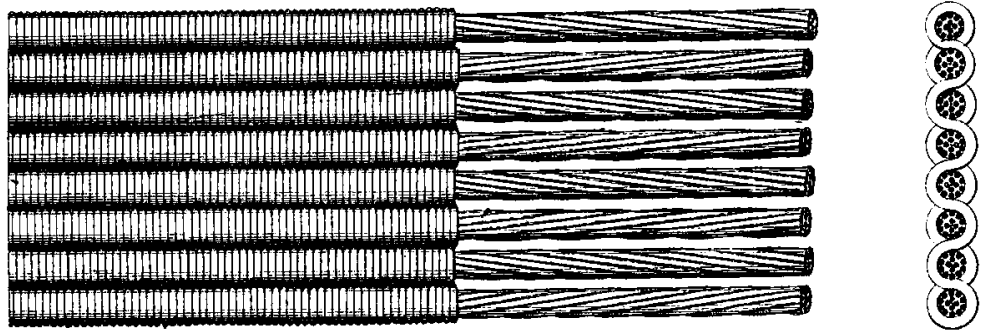

Fig. 31. Second Flat Wire Rope. 1837.

Fig. 32.
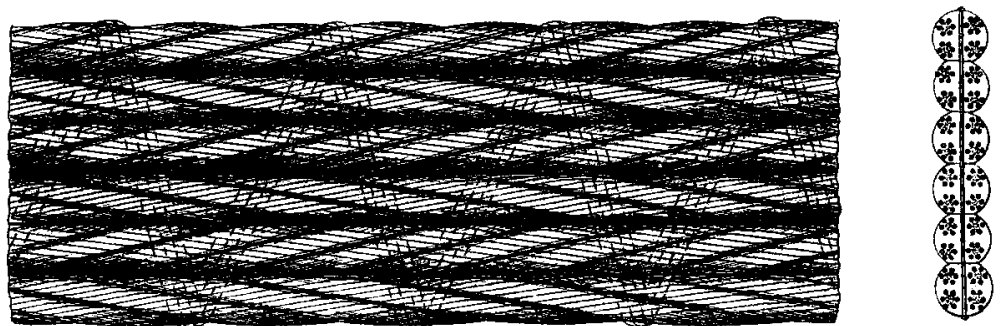
Fig. 33 .
"Laid" Wire
Rope.
1838

Fig. 34.
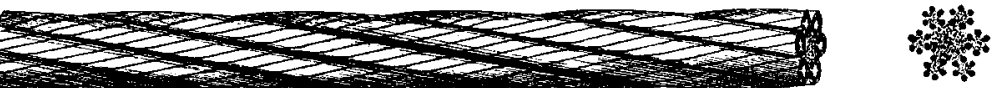

(Proceedings Inst.M.E. 1862. Page 1\%0.)

Scale 1/3rd full size. 


\section{Fig. 35 .}

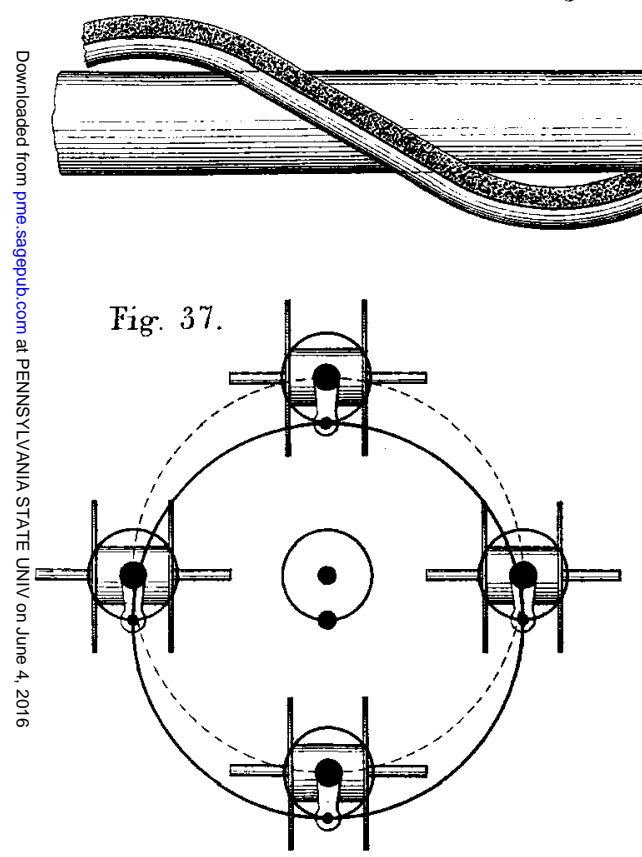

(Proceedings Inst. M.E. 1862. Page 170.)
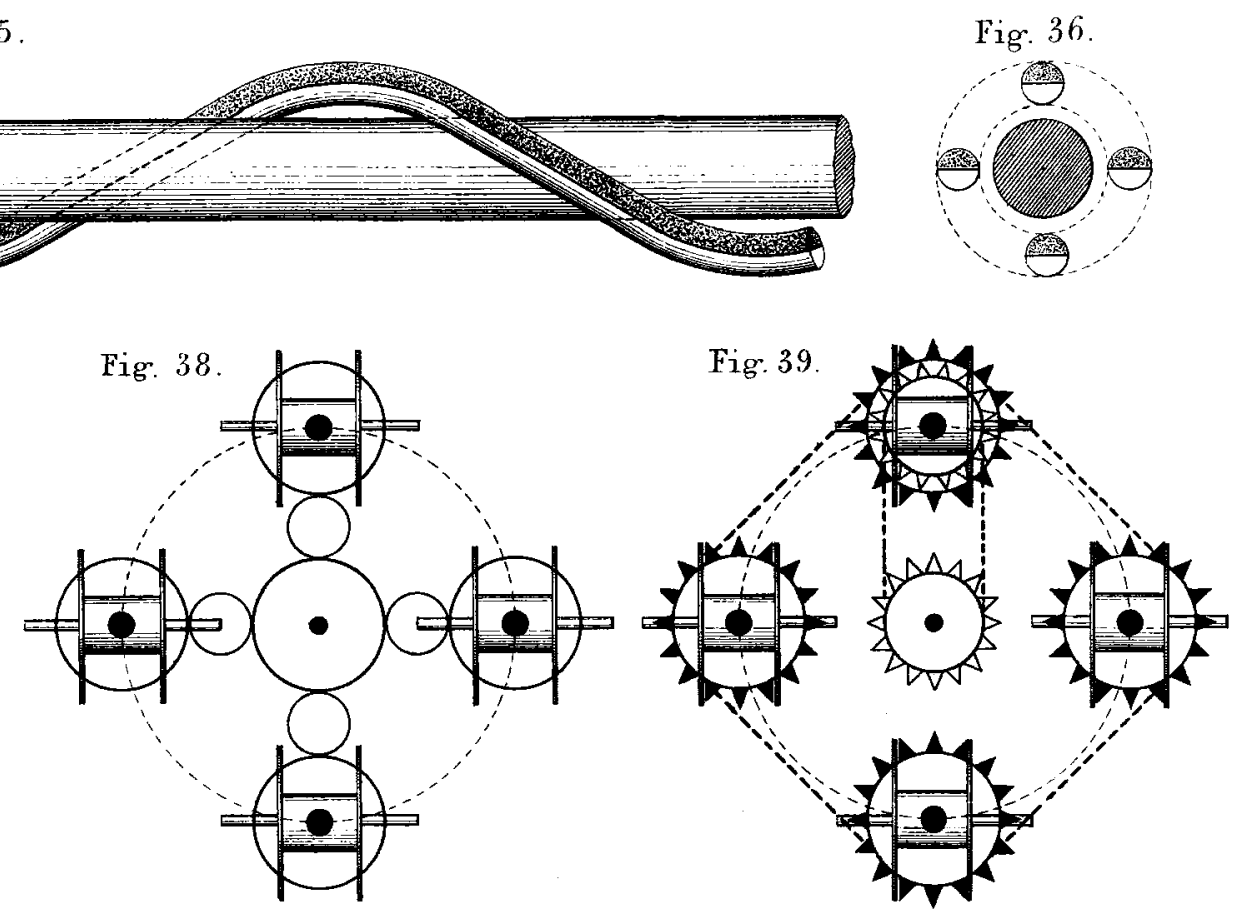
Huddart's Wire Rope Machine.

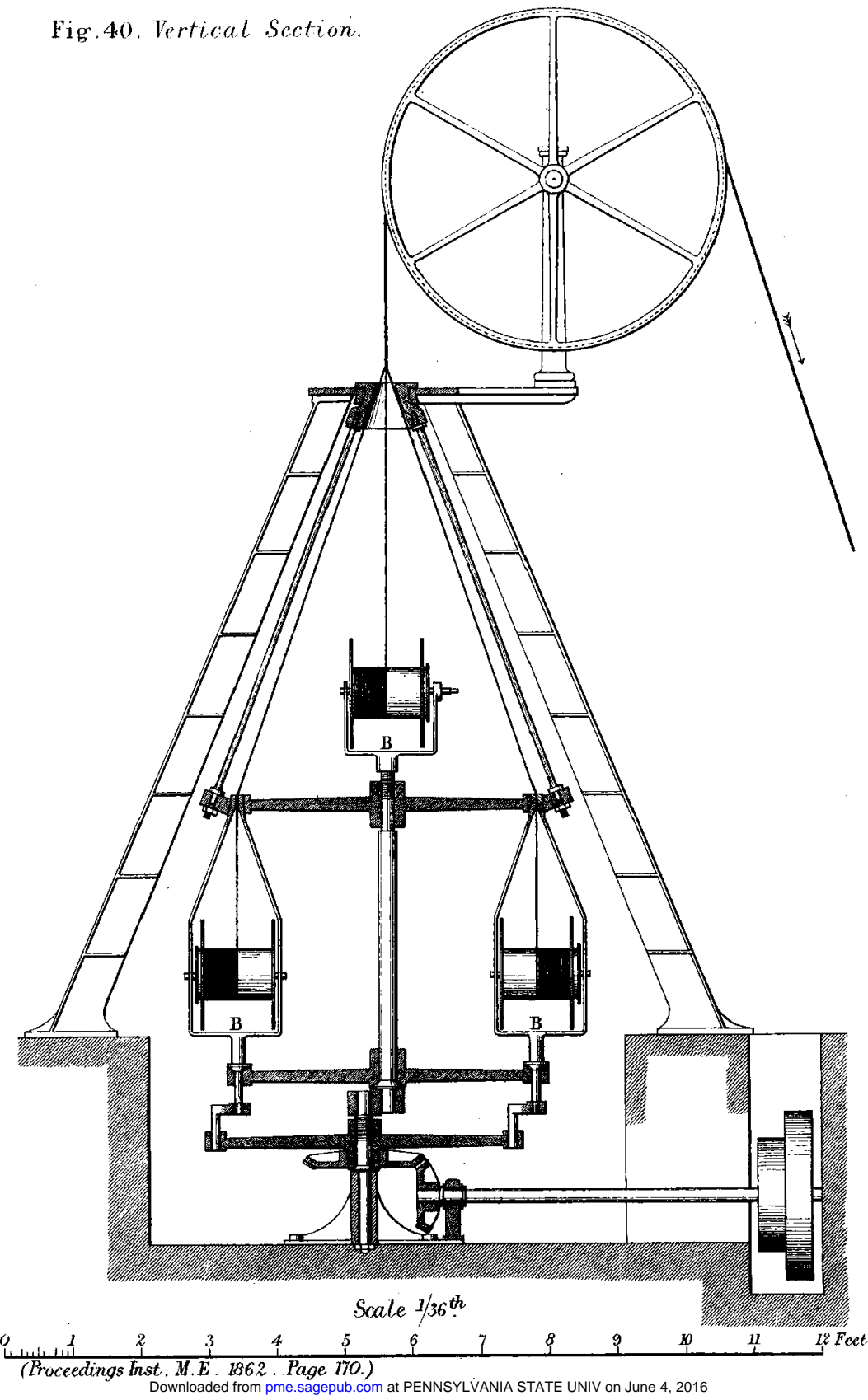




\section{ROPE MANUFACTURE.}

Smith's Wire Rope Hachine Fig.41. Side Elevation
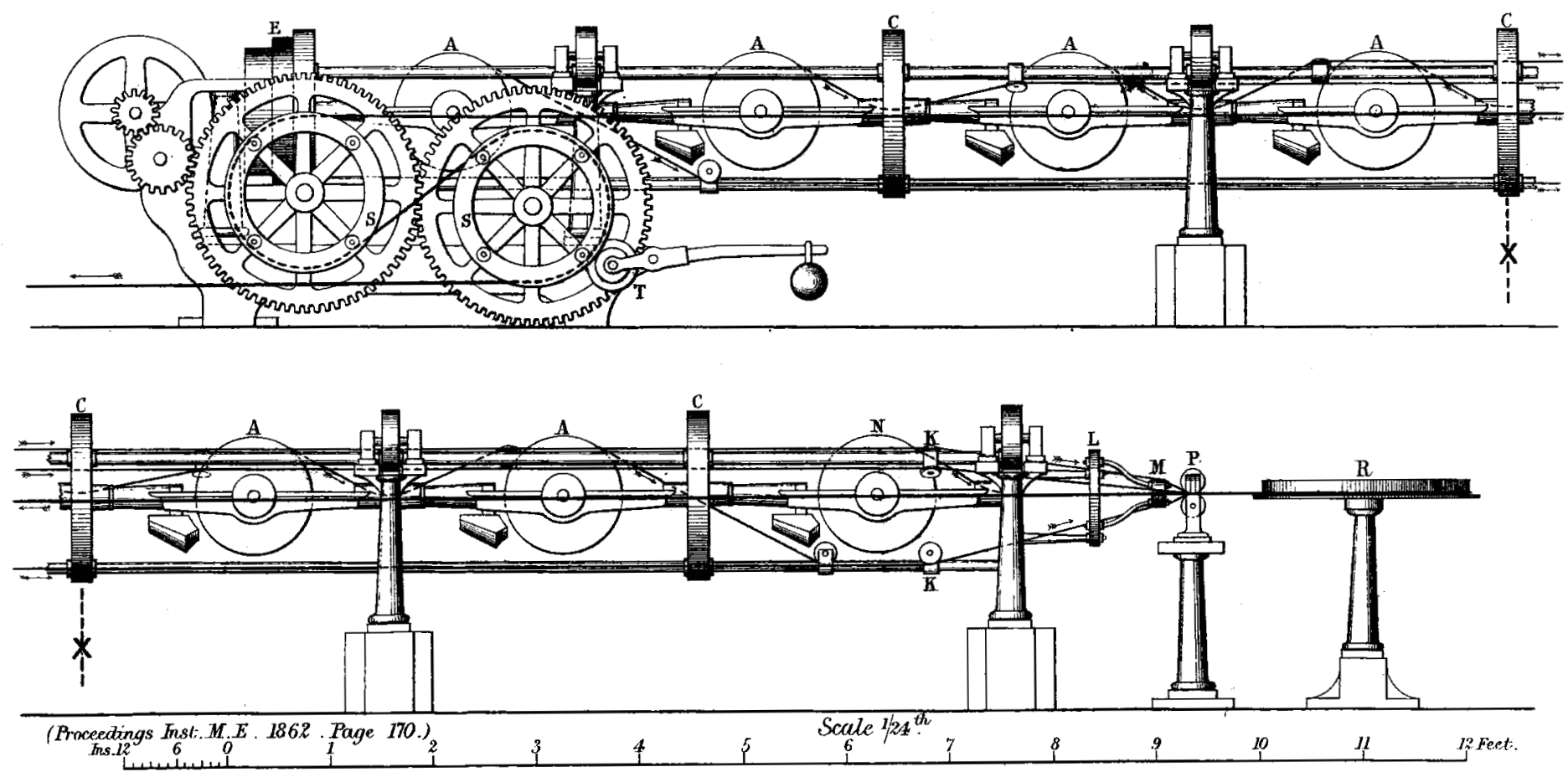

Downloaded from pme.sagepub.com at PENNSYLVANIA STATE UNIV on June 4, 2016 


\section{ROPE MANUFACTURE.}

Smith's Wire Rope Machine.

Fig. 42. Side Elevation. enlarged.

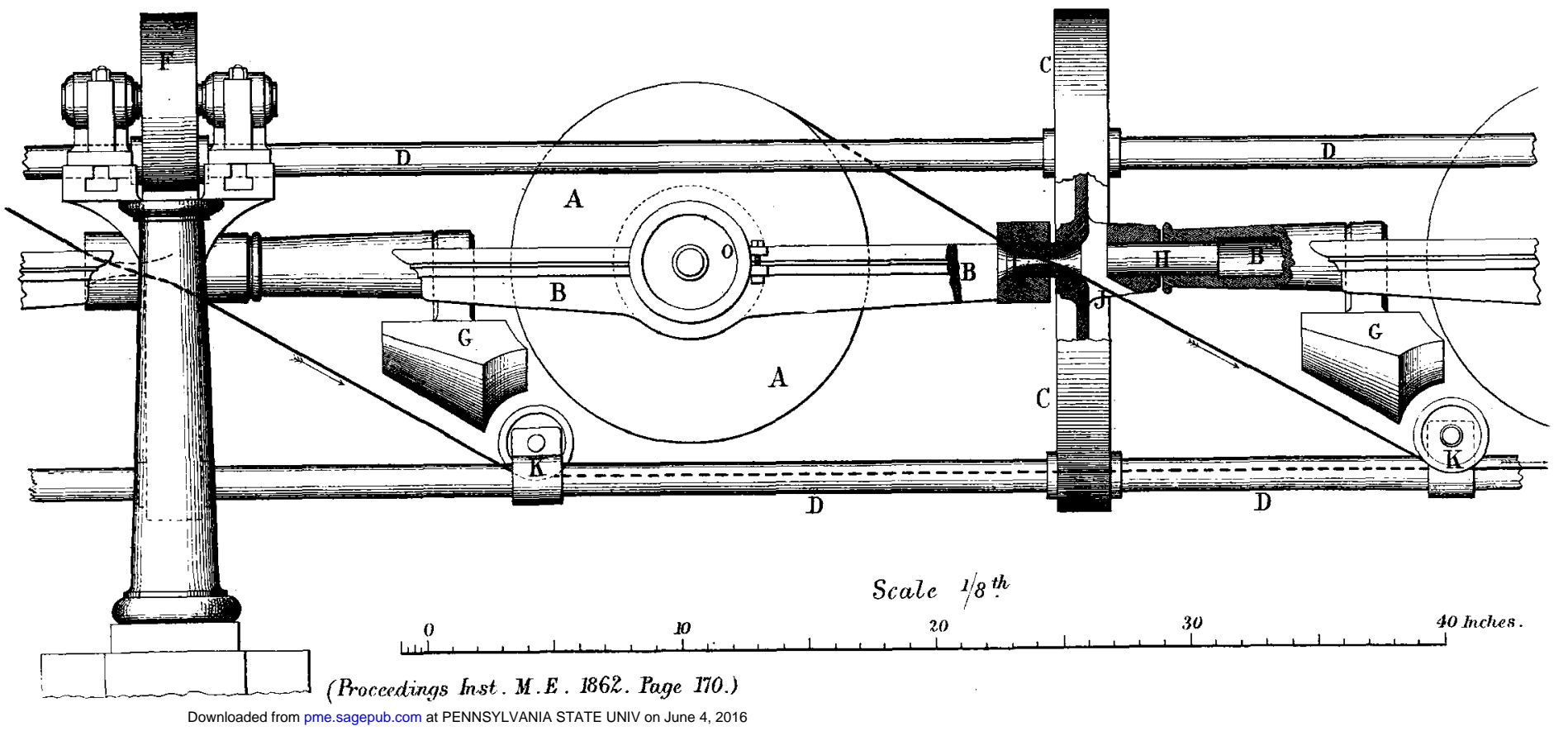


ROPE MANUFACTURE.

Plate 62.

Smith's Wire Rope Machine.

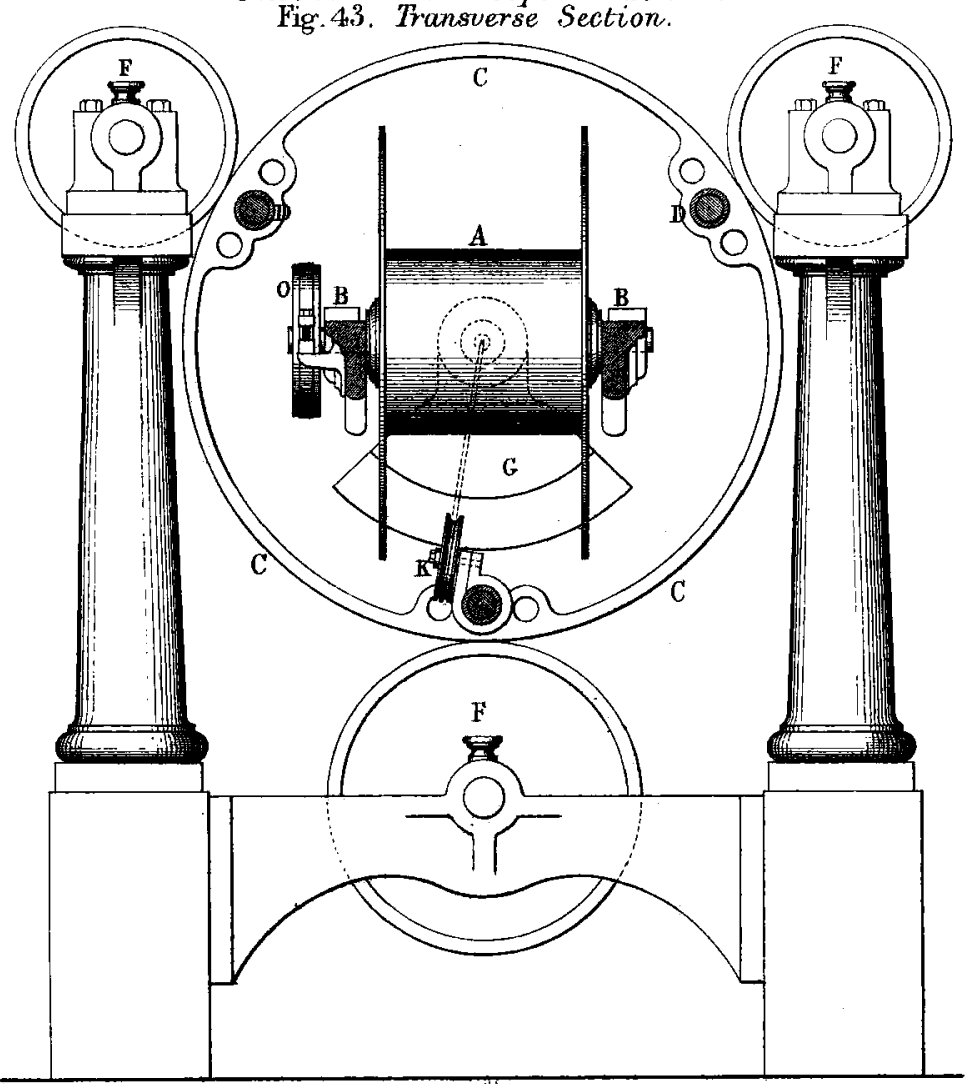

Fig.44. End Elevation.

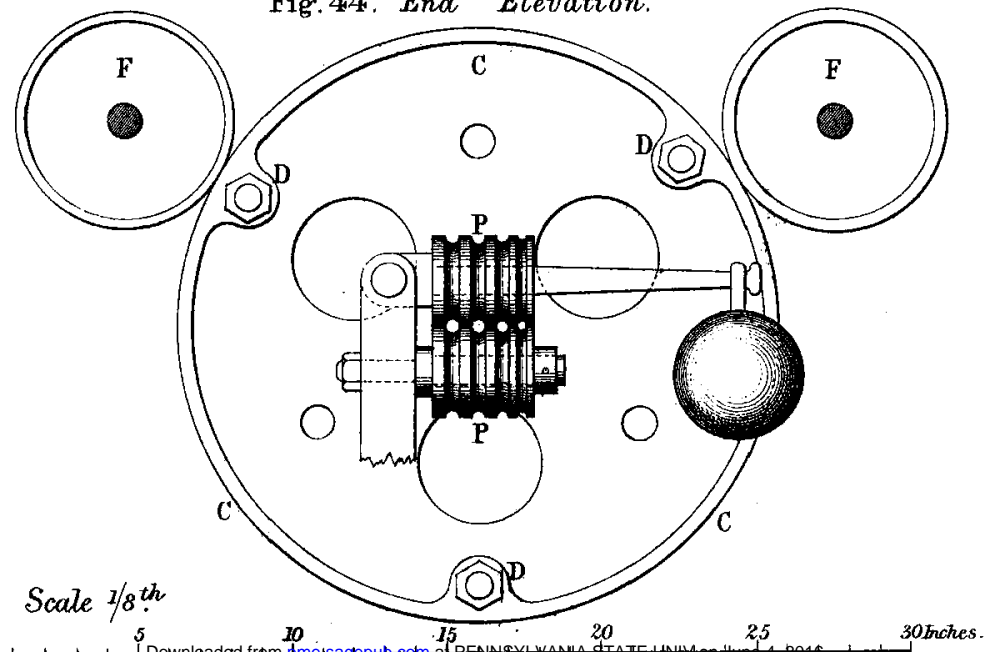

